Spring 6-14-2019

\title{
Body Forms in Sharks (Chondrichthyes: Elasmobranchii), and Their Functional, Ecological, and Evolutionary Implications
}

Phillip C. Sternes

DePaul University, philsternes77@gmail.com

Follow this and additional works at: https://via.library.depaul.edu/csh_etd

Part of the Biology Commons

\section{Recommended Citation}

Sternes, Phillip C., "Body Forms in Sharks (Chondrichthyes: Elasmobranchii), and Their Functional, Ecological, and Evolutionary Implications" (2019). College of Science and Health Theses and Dissertations. 327.

https://via.library.depaul.edu/csh_etd/327

This Thesis is brought to you for free and open access by the College of Science and Health at Digital Commons@DePaul. It has been accepted for inclusion in College of Science and Health Theses and Dissertations by an authorized administrator of Digital Commons@DePaul. For more information, please contact digitalservices@depaul.edu. 
Body Forms in Sharks (Chondrichthyes: Elasmobranchii), and Their Functional, Ecological, and Evolutionary Implications

\author{
A Thesis Presented in \\ Partial Fulfilment of the \\ Requirements for the Degree of \\ Master of Science
}

June 2019

By

Phillip C. Sternes

Department of Biological Sciences

College of Science and Health

DePaul University

Chicago, Illinois 


\section{Table of Contents}

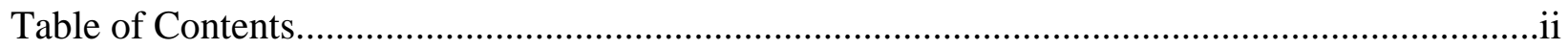

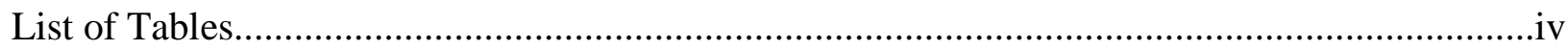

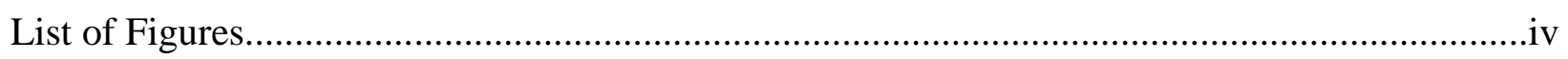

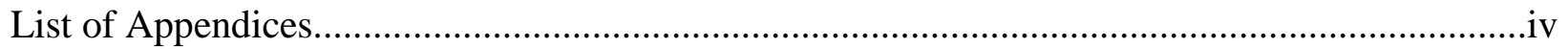

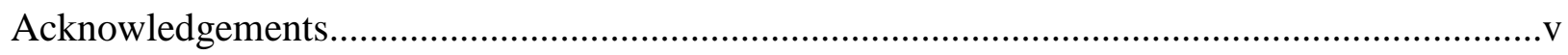

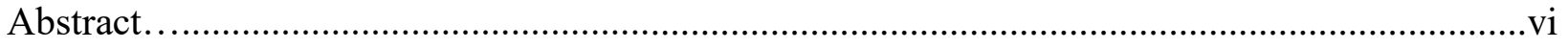

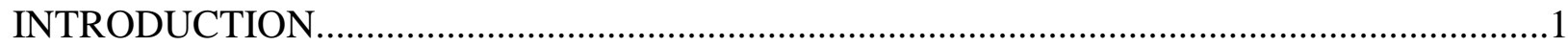

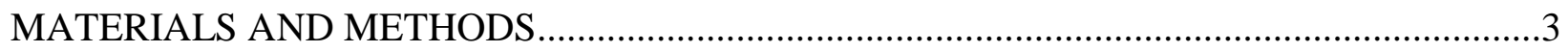

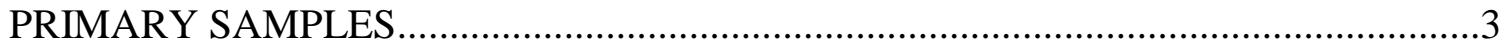

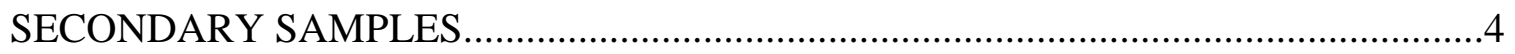

MORPHOMETRIC ANALYSES....................................................................

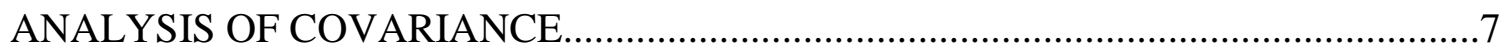

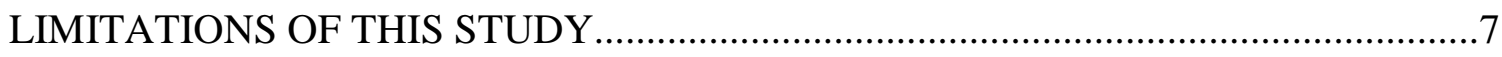

RESULTS

PILOT STUDY

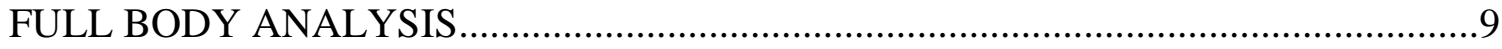

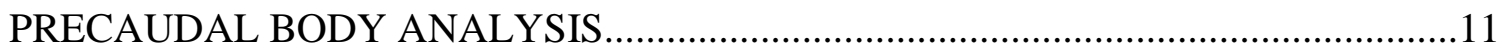

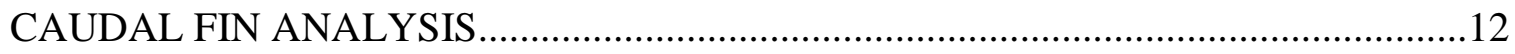

EFFECT OF SIZE ON SHAPE BY SHARK ORDER.................................................14

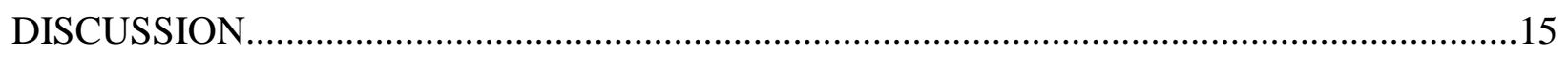

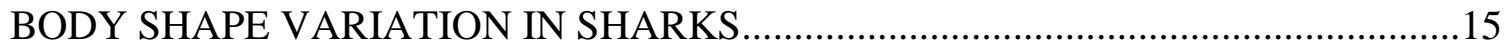




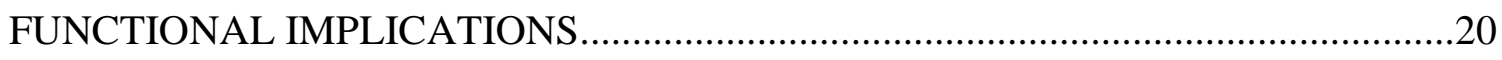

ECOLOGICAL IMPLICATIONS .................................................................... 21

EVOLUTIONARY IMPLICATIONS ................................................................ 23

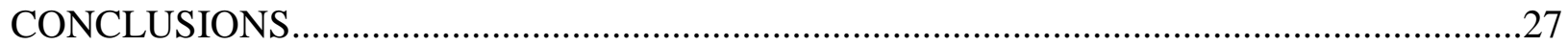

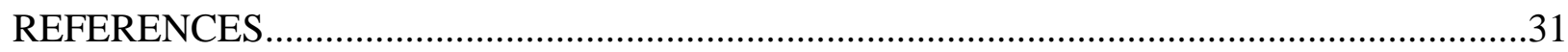




\section{List of Tables}

Table 1. List of shark taxa belonging to Group A and Group B based on this study..... 39

\section{List of Figures}

Figure 1. Previously published phylogenetic tree and four basic body forms in sharks.............41

Figure 2. Landmarks used for geometric morphometrics in this study.................................42

Figure 3. Diagram of pilot geometric morphometrics study...............................................43

Figure 4. Diagrams of geometric morphometric analyses on body form variation in sharks........44

Figure 5. Diagram of regression analysis on relationship of body size and shape in sharks........45

Figure 6. Diagram of geometric morphometric analysis of Thomson \& Simanek (1977) taxa...46

Figure 7. Possible evolutionary pathways of body forms in shark superorders...............47

\section{List of Appendices}

Appendix 1. List of species examined and their 'codes' used for the morphometric analyses.....48

Appendix 2. List of museum specimens used for pilot study..........................................60

Appendix 3. Scatter plot diagram of full body analysis with species codes............................62

Appendix 4. Scatter plot diagram of full body analysis with principal components 1 and $3 \ldots . .63$

Appendix 5. Scatter plot diagram of full body analysis with principal components 1 and $4 \ldots . . .64$

Appendix 6. Scatter plot diagram of full body analysis with principal components 1 and $5 \ldots \ldots 65$

Appendix 7. Scatter plot diagram of precaudal body analysis with species codes...................66

Appendix 8. Scatter plot diagram of caudal fin analysis with species codes..........................67 


\section{Acknowledgements}

I thank a vast amount of people for their support in this project. First, I would like to thank my family and friends for pushing me through and providing incredible encouragement until the very end. I thank the Department of Biological Sciences at DePaul University for their support and friendship. I thank my committee members Dr. Windsor Aguirre and Dr. Timothy Sparkes for their time and guidance that significantly improved the quality of my thesis. Lastly, I thank my thesis advisor Dr. Kenshu Shimada for his incredible patience and guidance over the course of my time at DePaul University.

For data collection, many individuals provided critical help in this project. First, I would like to thank Frank Guzzo and Riley Hacker (DePaul University) for their help in collecting caudal fin data, and Tim Cronin (DePaul University) for his help with part of my analyses. I thank all the collections managers and staff from various institutions as they were incredibly helpful and kind to provide their time and aid in this project. They include: Arnold Suzumoto (BPBM), Dave Catania, Jon Fong (CAS); William White (CSIRO); Caleb McMahan, Susan Mochel, Kevin Swagel (FMNH); Rick Feeney (LACM); Andy Williston, Meaghan Sorce (MCZ); Brian Sidlauskas, Mireya Vazquez (OS); Ralph Foster (SAMA); Philip Hastings, Ben Frable (SIO), Rob Robins, Lindsay French, Katie Boole (UF); Douglas Nelson (UMMZ); Jeff Fowler, and Sandra Raredon (USNM). 


\begin{abstract}
Sharks are among the oldest vertebrate lineages in which their success has been attributed to their diversity in body shape and locomotor design. In this study, I investigated the diversity of body forms in extant sharks using landmark-based geometric morphometric analyses on lateral view illustrations of nearly all the known (ca. 470) extant sharks in a published guidebook. I ran three different analyses: the 'full body,' 'precaudal body,' and 'caudal fin' analyses. My study suggests that there are two basic body forms in sharks. The two major body forms are characterized as a 'shallow-bodied' form (Group A) and 'deep-bodied' form (Group B). This pattern is also present in the precaudal body analysis, but the caudal fin analysis indicates that all sharks essentially have one basic caudal fin design. My geometric morphometric analyses have significant functional, ecological and evolutionary implications. First, I found that swimming modes in sharks are highly correlated with body forms. For example, Group A sharks are predominantly anguilliform swimmers, whereas Group B sharks are represented by carangiform and thunniform swimmers. Second, the majority of Group A sharks are found to be benthic whereas pelagic forms are relatively common among Group B sharks. Third, based on the known fossil record as well as previously published molecular-based phylogenetic trees, each of the two superorders of sharks, Squalomorphii and Galeomorphii, must have gone through complex evolutionary history where each superorder contains both Group A sharks and Group B sharks, possibly involving parallel evolution from one group to the other or at least one episode of evolutionary reversal. Lastly, the most ancestral shark, the clade that unites Squalomorphii and Galeomorphii, was possibly a benthic form with a Group A body form. My study demonstrates that a use of an identification guidebook can be a powerful method for the field of comparative anatomy.
\end{abstract}




\section{INTRODUCTION}

It is a well-known concept in biology that form is tightly related to its function (Russell, 1916), and such examination is significant because it is highly informative for making inferences about evolutionary and ecological relationships (Lauder et al., 1995). In the classical studies of Anolis lizards, those with longer hindlimbs can run across broad substrates whereas those with shorter limbs can balance on narrow branches (Losos, 1990, Kolbe et al., 2012). Among many other examples, another excellent case is the relationship between the body form of fishes and their mode of swimming where pelagic forms of fishes commonly exhibit a laterally compressed body whereas benthic forms are dorsoventrally flattened (Alexander, 1965; Webb, 1984; Weihs, 1989; Blake, 2004). The same pattern is particularly evident in elasmobranchs, a monophyletic group of cartilaginous fishes (Chondrichthyes), consisting of over 500 species of sharks (Selachii) under two superorders, Squalomorphii and Galeomorphii, and 630 species of rays (Batoidea) (Weigmann, 2016; Fig. 1A). In sharks alone, the white shark, Carcharodon carcharias (Linnaeus 1758), capable of fast-swimming and attacking highly mobile pinnipeds has a streamlined body, whereas bottom-dwelling angel sharks (Squatina spp.) wait in the substrate to ambush their prey have a dorsoventrally flattened body (Motta \& Huber, 2012).

Sharks have a long geologic history that appeared nearly 200 million years ago (Maisey et al., 2004; Grogan et al., 2012; Maisey, 2012), and they remain a major component of all marine ecosystems (Compagno, 1990). Their success is generally attributed to the vast diversity of their locomotor designs (Lauder \& Di Santo, 2016). Much of the work has focused on the morphology and function of their caudal fin referred to as heterocercal tail characterized by the upward flexure of the notochordal axis (Thomson, 1976; Thomson \& Simanek, 1977; Wilga \& 
Lauder, 2002; Maia et al., 2012). One of the pioneer works on classifying sharks according to different body forms is that by Thomson \& Simanek (1977). They recognized four basic body forms or "groups" of sharks using simple morphometric measurements based on 56 different species (Fig. 1B). Group 1 sharks are characterized by having a deep body, large pectoral fins, a caudal peduncle with lateral keels or a caudal fluke, and a symmetrical with a high-aspect ratio. An example of Group 1 sharks is the white shark, Carcharodon carcharias. Group 2 sharks have a body less deep then Group 1, no caudal fluke, and a low heterocercal angle. This group includes most carcharhinid sharks such as the bull shark, Carcharhinus leucas (Müller \& Henle 1839). Group 3 sharks have a very large head and blunt snout, more anteriorly positioned pelvic fins, more posteriorly placed first dorsal fins, and a low heterocercal angle with a large subterminal lobe and small or no hypochordal lobe, and catsharks (Scyliorhinidae) represent this group. The dogfish sharks (Squaliformes) represent Group 4 sharks characterized by a caudal fin with a higher aspect angle similar to that of Group 2 but lacking an anal fin.

Since Thomson \& Simanek's (1977) work, additional studies have explored the relationship between the body form and locomotion in sharks. For example, Scacco et al. (2010) examined the body morphometrics and swimming diversity of Mediterranean demersal sharks that revealed a change in body morphology as a function on swimming capabilities. Irschick \& Hammerschlag (2014) showed four different species of sharks with differing ecology and life history exhibit changes in the caudal fin through ontogeny (see also Reiss \& Bonnan, 2010). Subsequently, Iosilevskii \& Papastamatiou (2016) compared the body morphology of sharks with their buoyancy and energetics, and showed that larger sharks increase buoyancy to compensate for longer pectoral fins. More recently, Irschick et al. (2017) examined eight shark species to determine if ecology influenced body form. Despite all these studies, the four body 
groups proposed by Thomson \& Simanek (1977) have been assumed to capture the body form diversity in sharks (e.g., Maia et al., 2012; Shadwick \& Goldbogen, 2012; Irschick \& Hammerschlag, 2014; Lauder \& Di Santo, 2016; Irschick et al., 2017) even though their study was based on only about one-tenth (56 different species) of all known shark species using simple morphometrics.

The goal of this present study is to revisit Thomson \& Simanek's (1977) study by quantitatively examine the body form diversity in sharks. I examine nearly all the known (ca. 470) extant shark species included in the most recent comprehensive field guide of sharks, Sharks of the World: A Fully Illustrated Guide by Ebert et al. (2013), using landmark-based geometric morphometrics (Rohlf \& Marcus, 1993; Mitteroecker \& Gunz, 2009). Based on the results of my body shape analyses, I evaluate the variation of body forms in sharks, examine how my data correspond with Thomson \& Simanek's (1977) four basic body forms in sharks (Fig. 1B), and discuss the functional, ecological, and evolutionary implications of the newly observed body form patterms.

\section{MATERIALS AND METHODS}

\section{PRIMARY SAMPLES}

Thomson \& Simanek (1977) used illustrations of sharks from Bigelow \& Schroeder's (1948) The Fishes of the Western North Atlantic (Volume 1), that was arguably the most comprehensive literature with illustrations of diverse sharks available to them then. I used Thomson \& Simanek's (1977) strategy by basing my study on the most recent comprehensive guidebook of sharks, Sharks of the World: A Fully Illustrated Guide by Ebert et al. (2013) that was built on work by Bigelow \& Schroeder (1948) and many other subsequent landmark literatures on sharks 
(e.g., Compagno, 1984, 2002; Compagno et al., 2005). Ebert et al.'s (2013) book includes about 470 species of extant sharks that were known to science at the time when the book went into press. Although approximately 80 new species have been discovered since then (Weigmann, 2016; White et al., 2019), I did not include them in order to keep the quality of illustrations used to be consistent. For example, Ebert et al.'s (2013) illustrations include lateral drawings with a scale bar drawn by a single illustrator with a uniform method, including the left pectoral fin and pelvic fin that are consistently depicted to be ventrally directed (see review by Jawad, 2013; note that, unless otherwise indicated, one exception is Squatiniformes where only one lateral image is provided for the entire shark order). The exclusion of those recently described taxa were considered not to affect the overall result of my study, because they have phylogenetically close relatives with nearly identical body forms represented in Ebert et al.'s (2013) book. Appendix 1 shows all the species examined in this study, along with their 'species codes' used for the morphometric analyses (see below) as well as known maximum total length (TL) for each species and the page number in Ebert et al.'s (2013)'s book where each illustration can be found.

\section{SECONDARY SAMPLES}

As a 'fully illustrated' guidebook, the premise of Ebert et al.'s (2013) illustrations is that they are depicted as accurately as possible to allow identification of sharks. Nevertheless, I examined the caudal fin shape in one preserved, non-embryonic specimen of a representative species in each shark family to confirm, as a pilot study, the overall accuracy of Ebert et al.'s (2013) illustrations. Examined specimens belong to the following institutions: Bernice P. Bishop Museum (BPBM), Honolulu, Hawaii, USA; California Academy of Sciences (CAS), San Francisco, California, USA; Field Museum of Natural History (FMNH), Chicago, Illinois, USA; 
Florida Museum of Natural History, University of Florida (UF), Gainesville, USA; Museum of Comparative Zoology (MCZ), Harvard University, Cambridge, Massachusetts, USA; Museum of New Zealand Te Papa Tongarewa (NMNZ), Wellington, New Zealand; National Museum of Natural History, Smithsonian Institution (USNM), Washington D.C., USA; Natural History Museum of Los Angeles County (LACM), Los Angeles, California, USA; Oregon State University Ichthyology Collection (OS), Corvallis, Oregon, USA; Scripps Institution of Oceanography (SIO), University of California, San Diego, California, USA; South African Museum (SAM), Cape Town, South African; South Australian Museum, Adelaide (SAMA), Australia; University of Michigan Museum of Zoology (UMMZ), Ann Arbor, Michigan, USA. Appendix 2 lists specific taxa and specimens examined. I chose to focus specifically on comparing the caudal fins because 1) the precaudal body in preserved specimens is often dissected or fixed in a distorted posture (Glenn \& Mathias, 1987), and 2) because the caudal fin is a planar structure in which its shape can be traced easily and accurately.

\section{MORPHOMETRIC ANALYSES}

To explore the body form diversity in sharks quantitatively, I conducted three separate landmarkbased geometric morphometric analyses using MorphoJ 1.07a (Klingenberg, 2011). The first analysis, herein referred to as the 'full body analysis,' examined the entire body of the shark (i.e., precaudal body + caudal fin) in lateral view and used a total of 13 homologous landmarks as well as 100 semilandmarks (Fig. 2A). The second analysis, referred to as the 'precaudal body analysis,' focused on the shape of only the precaudal portion of the shark body of the shark in lateral view by excluding the caudal fin data from the total landmark data (i.e., 11 homologous landmarks and 60 semilandmarks: Fig. 2B). The third analysis, the 'caudal fin analysis,' focused 
only on the caudal fin shape in lateral view by excluding the precaudal body data from the total landmark data (i.e., four homologous landmarks and 40 semilandmarks: Fig. 2C). In this study, the second dorsal fin and anal fin were not taken into consideration because Echinorhiniformes and Squaliformes, respectively, lack them (see Ebert et al., 2013).

I followed Zelditch et al.'s (2012) methods, procedures, and protocols for morphometric analyses. First, all images of the sharks were scanned directly from Ebert et al.'s (2013) book. Computer software programs tpsUtil64 and tpsDig232 (Rohlf, 2015) were then used to create an electronic storage folder to upload and organize the image files and to digitize landmarks (Fig. 2). Instead of sequentially sampling from the first image in the book to the last image in the book, I made an effort to sample images of sharks from across different orders randomly throughout my digitization process. Whereas homologous landmarks could be decisively located (Fig. 3), semilandmarks were plotted along homologous curves to capture additional morphological information from each sample. These curves included dorsal and ventral curves of the precaudal body as well as the curves of each lobe from the caudal fin (Fig. 3). Each curve was digitized using the trace function in tpsdig232 and semilandmarks were appended to landmarks using tpsUtil64. The actual size of sharks was accounted by the accompanied scale bar in each scanned image using the measure tool also in tpsDig232. Next, another computer software, MorphoJ 1.07a (Klingenberg, 2011), was used to perform a Procrustes fit to generate a covariance matrix. A Procrustes fit eliminates differences in location, scale, and orientation of each sample, so that all samples are superimposed in shape measurement. The covariance matrix was then used to conduct each principal component analysis (PCA) as well as a shape change analysis. 


\section{ANALYSIS OF COVARIANCE}

The effect of size on shape is investigated routinely using geometric morphometrics (Klingenberg, 2016). Therefore, I examined if sharks differ in shape not only due to size but also if taxonomic classification plays a role in shape determination. I used an Analysis of Covariance (ANCOVA) to determine if taxonomic order ('factor') and shark size ('covariate') had an effect on overall shape in sharks ('response variable'). In this study, I chose to use the results of the precaudal body analysis, because many comparative papers on shark morphology (e.g., Irschick \& Hammerschlag, 2014; Fu et al., 2016; Irschick et al., 2017) relied on the use of the precaudal length (PCL). Furthermore, certain taxa (e.g., Alopias and Stegostoma) have caudal fins nearly the length of the body, possibly causing statistical outliers. Using my PCA data from precaudal body analysis, I obtained the size correction of each shark sample ('log centroid size') and mean overall shape of each sample (RegressionScore1 or 'shape score') from MorphoJ 1.07a. These data were organized based on taxonomic orders of sharks and were saved in a comma-separated value (CSV) file format for my ANCOVA using R version 3.5.2 (R Core Team, 2016).

\section{LIMITATIONS OF THIS STUDY}

There are two major limitations to this study that should be noted. First, this study examines the body forms of sharks only in lateral two-dimensional view and excludes other physical characteristics that may be potentially critical for understanding the full range of body form diversity in sharks, such as the head shape and body shape in dorsal view or their threedimensionality. However, whereas Thomson \& Simanek (1977) did discuss some observations regarding the head shape, it should be noted that their characterization of each of their four body forms (Fig. 1B) involved only the features observed from the lateral view with a potential 
exception of "blunt snout" for Group 3 sharks (see Introduction). Because the aim of this study is to revisit Thomson \& Simanek's (1977) study, I therefore chose to focus also on the lateral aspect of sharks. Second, the lack of the second dorsal fin and anal fin in Echinorhiniformes and Squaliformes, respectively, did not allow me to consider those fins because the geometric morphometric software, tpsDig232, did not allow any missing data, meaning that all selected homologous landmarks must be represented across all examined samples. In addition, Thomson \& Simanek's (1977) characterization of the four body forms included the knowledge about the presence or absence of lateral fluke at the caudal peduncle, but like with the second dorsal and anal fins, my geometric morphometrics cannot take this piece of anatomical information into consideration. Because my geometric morphometric study cannot take the three-dimensionality and certain aforementioned anatomical characteristics into account, conclusions drawn from this study, that constitutes the most comprehensive study of the body forms in sharks since Thomson \& Simanek's (1977) work, should still be considered working hypotheses.

\section{RESULTS}

\section{PILOT STUDY}

Before conducting the three analyses (see above), I ran a pilot study to confirm whether or not shark illustrations from Ebert et al.'s (2013) book reasonably reflect the morphology of actual sharks. I applied the same landmark scheme used for the caudal fin analysis (Fig. 2C) to the caudal fins of my 'secondary samples' (see above) and compared those with Ebert et al.'s (2013) illustrations. Appendix 2 lists all specimens used along with their species codes, and Figure 3 shows the results of my pilot study of one representative species from each family of sharks. A 
corollary of this pilot study is that the majority of the plots of Ebert et al.'s (2013) illustrations and those of my tracings of actual shark samples of respective species occur in close proximity in the morphospace. Although a minor spread between the two plots of each species is present that can be explained by intraspecific variation, the close proximity of the two plots, some of which even practically overlap one another, implies that the book illustrations represent the actual shark samples well. Furthermore, the fact that the book illustration and actual shark sample of each species occupy one specific region of the morphospace indicates that each species possesses a distinct shape relative to other shark species. Therefore, the outline of each shark species from Ebert et al.'s (2013) work is considered to capture adequately the shape of each species sufficient for the purpose of our study.

\section{FULL BODY ANALYSIS}

Figure 4A shows the color-coding scheme of each shark order used for plots of my full body analysis depicted in Figure 4B (for taxonomic identity of each plot, see Appendix 3). The first five principal components explain $84.89 \%$ of the total variation observed in shark body shape. The first principal component (PC1) explains $34.32 \%$ of the variation that is largely affected by the position of the first dorsal fin. Sharks with the first dorsal fin positioned more posteriorly on the precaudal body have lower PC1 values compared to those with a more anteriorly located first dorsal fin. The second principal component (PC2) explains $23.75 \%$ of the variation that is greatly affected by the aspect ratio of the caudal fin. Higher PC2 values are the result of low aspect ratio with a larger dorsal lobe and small to absent lower lobe, whereas lower PC2 values indicate a high aspect ratio caudal fin. The third principal component (PC3) explains $16.15 \%$ of the variation that is mainly affected by the location of the pelvic fins. Sharks with pelvic fins more posteriorly placed score higher compared to sharks with more anteriorly placed pelvic fins. The 
fourth principal component (PC4) explains $7.29 \%$ of the variation. It is affected by the overall length of the pectoral fin, where sharks with shorter pectoral fins score higher PC4 values than those with longer pectoral fins. The fifth principal component (PC5) explains 3.38\% of the total variation that is largely affected by the depth of the lower lobe of the caudal fin, where sharks with a deeper lower lobe scores lower than sharks with a narrower lower lobe.

My full body analysis plotting the relationship between PC1 and PC2 (Fig. 4B) reveals that there are two major divisions in shark body shape. The same pattern is also observed even when changing the $y$-axis in the scatter plot diagram to PC3, PC4, or PC5 (Appendices 4-6). Therefore, I consider PC1 and PC2 alone adequately capture the overall body form patterns in sharks where the discussion hereafter focuses specifically on PC1 and PC2. In general, members of each shark order cluster together to occupy one specific region of the morphospace with the exception of Carcharhiniformes and Lamniformes. Hexanchiformes, Pristiophoriformes, Squatiniformes, Orectolobiformes (except Stegostomatidae: see below), and the catshark species (Scyliorhinidae) of Carcharhiniformes, occupy the top left side of the overall plot distribution due to the posterior position of their first dorsal fin within the precaudal body. Echinorhiniformes, shows a split distribution with one species located in the left major cluster whereas the other is located between the two major clusters. Squaliformes, Heterodontiformes, Lamniformes (except Alopiidae: see below), and houndshark and requiem shark species (Triakidae and Carcharhinidae) of Carcharhiniformes occupy the top right side of the overall plot distribution. Relative to other shark orders, Lamniformes shows the greatest distribution especially because the thresher sharks, Alopias spp. (Alopiidae), fall outside the larger plot distribution together with one orectolobiform, the zebra shark or Stegostoma faciatum (Hermann 
1783) (Stegostomatidae), because of their exceptionally elongated caudal fin (i.e., three dark green and one light blue plots in the lower left corner of Fig. 4B).

\section{PRECAUDAL BODY ANALYSIS}

The first five principle components explain $91.63 \%$ of the total variation of the precaudal body shape in sharks. Similar to the full body analysis, PC1 explains $47.84 \%$ of the variation, stemming largely from the position of the first dorsal fin. Sharks with a more posteriorly located first dorsal fin have lower PC1 scores, whereas those with higher PC1 scores have a more anteriorly located first dorsal fin. PC2 explains $25.49 \%$ of the total variation in precaudal body shape in sharks, and it is mainly linked to the position of the pectoral and pelvic fins. Higher PC2 values are associated with pectoral and pelvic fins that are positioned closely to one another; in contrast, lower PC2 values are associated with widely separated pectoral and pelvic fins. PC3 explains $9.53 \%$ of the total variation primarily from the dorsal ventral length of the pectoral fin, where sharks with shorter pectoral fins score higher compared to sharks with longer pectoral fins. PC4 explains $5.40 \%$ of the total variation and is affected by the curvature of the pectoral fins. Sharks with shorter but highly curved pectoral fins score higher compared to sharks with longer more pointed pectoral fins. PC5 explains $3.37 \%$ of the total variation that stems from the dorsal ventral depth of the posterior half of the precaudal body. Sharks with a narrower posterior half of the precaudal body score higher compared to sharks with a deeper posterior half of the precaudal body.

Figure $4 \mathrm{C}$ depicts the result of my precaudal body analysis showing the relationship between PC1 and PC2 (see Fig. 4A for color-coding scheme; for taxonomic identity of each plot, see Appendix 7) that exhibits a similar distribution pattern of plots to the full body analysis (Fig. 
4B). Overall, members of each shark order clusters tightly together to occupy one specific region with the exception of a major division in Carcharhiniformes. Plots of Hexanchiformes, Squatiniformes, Orectolobiformes, and scyliorhinid (catsharks) Carcharhiniformes are clustered together on the left side of the diagram, whereas the right side of the diagram are occupied by plots of Squaliformes, Heterodontiformes, Lamniformes, and the houndsharks (Triakidae) and requiem sharks (Carcharhinidae) of the Carcharhiniformes. Unlike the full body analysis, however, plots of Pristiophoriformes are conspicuously distributed between the two aforementioned major clusters of plots, and the two known species of Echinorhiniformes are uniquely located on the bottom left region the diagram.

\section{CAUDAL FIN ANALYSIS}

The first five principle components explain $90.81 \%$ of the total variation observed in the caudal fin shape of sharks. PC1 explains $51.18 \%$ of the variation and is associated with the aspect ratio of the caudal fin. Sharks with higher PC1 scores have a caudal fin with a high aspect ratio, whereas those with low aspect ratios have lower scores. PC2 explains $24.12 \%$ of the total variation, and it is associated with the overall depth of the upper lobe of the caudal fin. Sharks with a larger, more pronounced upper lobe have higher PC2 scores compared to those with a narrower upper lobe. PC3 explains $8.39 \%$ of the total variation and is associated with the depth of the tip of both the upper and lower lobes. Sharks with deeper fin tips score higher compared to sharks with narrower tips. PC4 explains $3.76 \%$ of the variation, and it is mainly associated with the angle of the ventral lobe at its origin where sharks with a larger angle score higher compared to those with a lower angle. PC5 explains $3.37 \%$ of the total variation caudal fins, and it mainly focused on the depth of both the upper and lower lobes where sharks with narrow upper lobes 
but deeper lower lobes score higher than sharks with deeper upper lobes but narrower lower lobes.

Figure 4D shows the result of my caudal fin analysis that plots PC1 against PC2 (see Fig. 4A for color-coding scheme; for taxonomic identity of each plot, see Appendix 8). The plots (Fig. 4D) display wide distribution without any major division unlike the full body and precaudal body analyses (Fig. 4B, C). Nevertheless, members of each shark order tend to cluster close together, filling its own space in the morphospace with the arguable exception of Lamniformes. For example, Echinorhiniformes, Pristiophoriformes, and the majority of Orectolobiformes and Carcharhiniformes are found towards the left half of the total range of plot distribution, whereas Hexanchiformes, Squaliformes-Echinorhiniformes, and Heterodontiformes are distributed, respectively, at the bottom center, center, and top center of the total plot distribution range. Squatiniformes uniquely occurs in the upper right corner of the morphospace, Lamniformes and the remaining species of Carcharhiniformes and Orectolobiformes are located on the right half of the total plot distribution range, although Lamniformes occur in three distinct clusters: 1) a cluster of three outliers at the bottom center represented by Alopiidae, 2) a cluster of six plots to the far right side of the scatter plot diagram consisting of Cetorhinidae (basking shark) and Lamnidae (white, mako, salmon, and porbeagle sharks), and 3) a cluster near the center of the diagram represented by the remaining lamniform taxa (Mitsukurinidae. Odontaspididae, Pseudocarchariidae, and Megachasmidae). One outlier of Orectolobiformes that occurs together with the Cetorhinidae-Lamnidae cluster is the whale shark, Rhincodon typus Smith 1829 (Rhincodontidae). 


\section{EFFECT OF SIZE ON SHAPE BY SHARK ORDER}

Figure 5 shows the results of my ANCOVA to examine the effect of size on shape by each shark order. A confidence ellipse is included for each shark order to show the spread of its splits in the scatter plot diagram. Figure 5A shows the location of taxonomic orders in the scatter plot diagram of mean overall shape against size. Among all shark orders, Carcharhiniformes shows the largest overall shape variation when measured against size with the slope of the confidence ellipse (Fig. 5A). The remaining graphs (Figure 5B-F) depict how size effects of shark order in relation to the first five principle components (PC1-PC5) in which they explain most $(84.89 \%)$ of the total shape variation observed in sharks. Similar to mean overall shape against size (Fig. 5A), PC1 against size shows that Carcharhiniformes is most affected by size as compared to the other shark orders (Fig. 5B). My analyses of size against PC2 (Fig. 5C) and PC3 (Fig. 5D) show that most shark orders have shape differences due to size although the differences in the case of PC3 are not as large as that of PC2. In my analyses of size against PC4 (Fig. 5E) and PC5 (Fig. 5F), only Pristiophoriformes shows rather large shape differences by size. Whereas such differences may observed in isolated morphological features, overall, when all sharks are combined and examined together as a whole (Fig. 5A), my analysis indicates that size does have an effect on overall body shape (ANOVA: $d f=1,452 ; F=243.54 ; p<0.001$ ). Additionally, my analysis shows that each taxonomic order also differ in mean shape (ANOVA: $d f=1,452 ; F=$ $2.2 ; p<0.05)$. 


\section{DISCUSSION}

\section{BODY SHAPE VARIATION IN SHARKS}

Thomson \& Simanek (1977) examined 56 species of sharks represented by a wide taxonomic range, where the four body form groups (Fig. 1B) have continued to be the basis of subsequent studies (e.g., Irschick \& Hammerschlag, 2014; Irschick et al., 2017) and reviews on shark morphology and body mechanics (e.g., Maia et al., 2012; Shadwick \& Goldbogen, 2012; Lauder \& Di Santo, 2016). However, my landmark-based geometric morphometric analyses clearly show that there are two broad categories of body forms, rather than four, among extant sharks (Fig. 4B). The major source of the division comes from the morphology of the precaudal portion of the body (Fig. 4C) and not from the shape of the caudal fins (Fig. 4D). One of the two major groups, that is located on the left side of the scatter plot diagram (Fig. 4B), consists of elongated ('shallow-bodied') fusiform carcharhiniforms and hexanchiforms as well as dorsoventrally flattened ('shallow-bodied') orectolobiforms, pristiophoriforms, and squatiniforms. For the purpose of this study, I refer this group to 'Group A' sharks. The other major group located on the right side of the scatter plot diagram (Fig. 4B) consists of stout ('deep-bodied') fusiform sharks, including the remaining carcharhiniforms, heterodontiforms, lamniforms, and the vast majority of squaliforms. This assemblage of sharks is referred herein to 'Group B' sharks. The four specific outliers, Stegostoma faciatum and the three species of Alopias, seen in the bottom left corner of the scatter plot diagram (Fig. 4B) are characterized by an exceptionally elongate caudal fin that is as long as the precaudal body. However, my precaudal body analysis (Fig. 4C) does not find those four species to be distinctively different. Therefore, I regard S. faciatum to be an extreme form of Group A, and Alopias spp. an extension of Group B (Fig. 4B). In addition, it 
is noteworthy that the two echinorhiniform species and a few species of Squaliformes (cookiecutter and pygmy sharks: Isistius brasiliensis (Quoy \& Gaimard, 1824), I. labialis Meng et al., 1985, I. plutodos Garrick \& Springer, 1964 and Euprotomicrus bispinatus (Quoy \& Gaimard, 1824)) occur in the gap between Groups A and B with their tendency towards Group A. However, because they do not form any distinct clusters, they do not merit a separate group assignment. Based on these interpretations, Table 1 lists shark taxa belonging to each of the two groups. Although Group A (245 species) and Group B (259 species) have similar total numbers of species, Group A (44 genera) has a noticeably smaller generic diversity than Group B (60 genera).

Thomson \& Simanek (1977) noted that the position of the first dorsal fin and the aspect ratio of the heterocercal caudal fin represent the two most important factors that determine the body form in sharks and formed the basis of differentiating their four body form groups (Fig. 1B). Based on my full body analysis (Fig. 4B), I found their proposition to be true. For example, most of the variation from PC1 was the result of the position of the first dorsal fin. A more posteriorly located first dorsal fin would result in a negative value placing sharks on the left side of the scatter plot diagram, whereas a more anteriorly placed first dorsal fin would result in a positive value placing sharks on the right side of the diagram. Likewise, much of the variation in PC2 was due to differences in the aspect ratio of the caudal fin. Sharks with a more upright caudal fin would lead to a negative value placing them in the bottom region of the diagram, whereas those with a low aspect ratio would place them in the top region of the diagram. It is worth noting that I found no additional body shape divisions in sharks in the full body analysis when using PC3, PC4, or PC5, in place of PC2, although there was some segregation by 
taxonomic order (see Appendices 4-6) suggesting some morphological differences are present but confined to each order.

My precaudal body analysis did not account for the caudal fin data that would correspond to PC2 in the full body analysis. Yet, the scatter plot diagram resulted in two major divisions (Fig. 4C) that are essentially identical to Group A and Group B found in the full body analysis (Fig. 4B). This finding strongly suggests that the precaudal body shape has a much stronger influence over the overall body forms than to the caudal fin shape in sharks. The plot distributions of orectolobiforms and elongated carcharhiniforms overlap nearly completely as in the full body analysis (Fig. 4B, C), but hexanchiforms and echinorhiniforms as well as dorsoventrally flattened pristiophoriforms and squatiniforms are noticeably diverged from the main cluster of Group A. Sharks of Group B in the full body analysis are also represented in the major cluster on the right side of the diagram (i.e., squaliforms, heterodontiforms, lamniforms. and the stout carcharhiniforms); however, the plots are likewise distributed more widely in the precaudal fin analysis (Fig. 4C) than the full body analysis (Fig. 4B).

Thomson \& Simanek (1977) noticed that the positions of the dorsal, pectoral, and pelvic fins to be key features that influence the body forms in sharks where the positions of the latter two types of fins were the basis for the recognition of their Groups 3 and 4 sharks (Fig. 1B). My study shows that the variable causing the most variation in the precaudal body shape is the position of the first dorsal fin (PC1), followed by the position of the pectoral and pelvic fins (PC2). A large separation between the pectoral fin to the pelvic fin resulted in a lower score placing such sharks in the lower half of the scatter plot diagram, whereas the pectoral and pelvic fins that were placed closely to each other resulted in a higher score. 
The caudal fin of sharks is typically regarded to show a wide range of variation (e.g., Thomson, 1976; Thomson \& Simanek, 1977; Scacco et al., 2010). However, unlike the full body and precaudal body analyses, my caudal fin analysis shows no major division of plots. Instead, although each order tends to occupy its own region in the morphospace, plots overall occur as one large cluster, suggesting that different forms of caudal fin recognized (e.g., Thomson \& Simanek, 1977, fig. 6) are essentially variation of one basic design. A few notable extremes of the continuum are Squatiniformes with a significantly large ventral lobe compared to most sharks, Cetorhinidae, Lamnidae, and Rhincodontidae with a nearly symmetrical, lunate caudal fin, and Alopiidae with an exceptionally elongated whip-like dorsal lobe.

There are two major distinct body forms, Group A and Group B (Fig. 4B), recognized, but it is worth noting that Group A comprises two seemingly different forms, sharks with elongated fusiform body and dorsoventrally flattened forms. Whereas my examination that focused on the body form only in lateral profile may have a risk of over-generalizing the body forms (see 'Limitations of This Study' above), both body forms can nevertheless be characterized as 'shallow-bodied' sharks, that rather sharply contrasts Group A sharks with a deep-bodied fusiform precaudal design.

At first glance, the recognition of only two major body forms (Fig. 4B) would appear also not to support Thomson \& Simanek's (1977) four basic body forms in sharks (Fig. 1B). However, it is noteworthy that Thomson \& Simanek's (1977) four body form groups are not randomly distributed. Figure 6 is essentially the same scatter plot diagram as the full body analysis shown in Figure 4B but plots only species of the genera included in Thomson \& Simanek's (1977) study with each of the four body form groups identified (Fig. 1B) in addition to pristiophoriform and squatiniform sharks that have a dorsoventrally flattened body. Sharks of 
Thomson \& Simanek's (1977) Groups 1, 2, and 4 as well as some Group 3 represent my Group B sharks, whereas the remaining sharks of Group 3 represent my Group A sharks. Furthermore, within my Group B cluster, sharks of Group 3 tend to occupy the upper region, followed downward within the cluster by sharks of Group 4, Group 1, and Group 2. Sharks of Group 3 are also represented in my Group A, some of which are suggestive of possessing a body depth as low as pristiophoriform and squatiniform sharks. This fact, combined with Thomson \& Simanek's (1977) four body form groups occupying different regions of the morphospace within my Group $\mathrm{B}$, indicates that there may be arguably as many as six subcategories of body forms in sharks if pristiophoriform and squatiniform sharks are considered to be a separate category by having a flat ventral body surface. However, the merit of decisively defining the six subcategories is uncertain because the separations among the subcategories in each of the two major clusters are not as sharp as the separation between Group A and Group B.

My morphometric study suggests that there are two major body forms in sharks (Fig. 4B). However, there are also some indications based on my ANCOVA that the overall body shape variation may be in part affected by the body size and taxonomic order (Fig. 5A). A similar observation was also noted by Irschick et al. (2017) even among the eight species of sharks they examined in their morphological study. In addition, my ANCOVA appears to suggest that there are also body shape differences based on taxonomic orders, although this is not necessarily surprising because some shark orders (e.g., Squaliformes, Orectolobiformes, and Lamniformes) have a wide range of interspecific size variation, whereas other orders are represented by species of similar sizes (e.g., Pristiophoriformes and Heterodontiformes) (see Ebert et al., 2013). Nevertheless, the division of the two major body form groups identified in my study (Fig. 4B) is quite sharp raising the possibility that the size and taxonomic effects on body shape can be 
regarded as less important when discussing the functional, ecological, and evolutionary implications of the two body forms below.

\section{FUNCTIONAL IMPLICATIONS}

The study of the relationship between body form and swimming mechanism in fishes has a long history and is a central concept in understanding fish ecology and evolution (Breder, 1926; Lindsey, 1978; Webb, 1984; Blake, 2004). Swimming is defined as movement through water by propulsion of the body or body parts (Gray, 1933; see also Lindsey, 1978), and the two major modes of swimming in fishes are oscillatory and undulatory motions (Webb, 1984). The oscillatory motion is described as a propulsive structure swiveling on its base to generate thrust (e.g., Batoidea or rays), whereas the undulatory motion uses thrust to swim by bending the body in a backward-moving propulsive wave that extends into the caudal region (Sfakiotakis et al., 1999). The undulatory motion can be further divided into anguilliform, subcarangiform, carangiform, and thunniform modes (Breder, 1926; Lighthill, 1975; Webb, 1984; Sfatiokakis et al., 1999). Sharks use three of these four modes: anguilliform, carangiform, and thunniform (Maia et al., 2012; Lauder \& Di Santo, 2016). Some species of sharks have been heavily studied in regards to swimming mode whereas many others remain uninvestigated (Lingham-Soliar, 2005; Maia et al., 2012; Shadwick \& Goldbogen, 2012; Maia \& Wilga, 2016). Nevertheless, Maia et al. (2012) assigned one of the three swimming modes to each of many shark taxa consisting of a wide range of lineages, and they are summarized in Table 1. One striking observation that can be gleaned from the distribution of the three swimming modes in Table 1 is that Group A almost entirely consists of anguilliform sharks whereas Group B consists of carangiform and thunniform sharks. 
Table 1 strongly suggests that, in sharks, swimming modes are highly correlated with body forms. Anguilliform is described as 'eel-like' swimming in which the entire trunk and caudal fin undulate with several waves transmitted through the body axis, whereas carangiform shows limited lateral movement that is mostly confined to the posterior half of the body (Maia et al., 2012). Thunniform has the least lateral movement of the body in which the movement is restricted to the caudal fin from the caudal peduncle (Maia et al., 2012). My study demonstrates that the shallower-bodied forms (Group A sharks) swim with more undulatory lateral movements throughout the body axis compared to the deeper-bodied sharks (Group B sharks with a more stout girth) with restricted lateral movement confined largely to the posterior portion of the body. Similar trends are also observed in many other fish taxa (see Blake, 2004).

\section{ECOLOGICAL IMPLICATIONS}

Sharks exhibit a great diversity in their habitat and depth distribution in the marine ecosystem (Compagno, 1990). For example, Dulvy et al. (2014) attempted to assign sharks to one of five possible habitats, including (1) coastal and continental shelf, (2) pelagic, (3) meso- and bathypelagic, (4) deepwater, and (5) freshwater. However, because habitat data of shark species are not reported in a consistent manner, decisively assigning a specific Dulvy et al.'s (2014) habitat category to every known shark species is not possible at the present time. However, I attempted to divide the habitats of shark genera into two broad categories, benthic and pelagic, based on the habitat information provided by Ebert et al. (2013). If the preferred habitat of a shark taxon was described using one or more of the following expressions, it was categorized as 'benthic': 'benthic,' ‘on muddy bottom,' ‘along continental shelves,' 'on sediment,' 'bottom on insular continental shelves,' or 'near continental shelves.' The following expressions were 
categorized as 'pelagic': 'pelagic,' ‘epipelagic,' 'bathypelagic,' 'open ocean,' or 'oceanic.' My dichotomous scheme (benthic vs. pelagic) used in this study is appreciably coarse, where nonobligatory benthic sharks, such as demersal forms (e.g., Carcharias, Dalatias, Odontaspis, Rhizoprionodon, etc.) are even classified as 'benthic.' However, this decision is deliberate in order to tease out the 'true pelagic forms' conservatively by broadening the range of the benthic regime, because my goal is to examine the differences in the proportion between benthic and pelagic sharks in each body form group (Group A vs. Group B). Table 1 summarizes the categorizations denoted by genera in bold or with an asterisk.

Table 1 clearly shows that Group A is dominated by benthic sharks, whereas pelagic forms are more common in Group B relative to Group A. Only three of the 44 Group A genera are pelagic, and only seven species among the 245 species (i.e. only $2.86 \%$ ) in Group A are pelagic. On the other hand, 21 of the 60 Group B genera are pelagic, where 66 species among the 259 species $(25.48 \%$ ) are pelagic in Group B. If the sharks that are 'occasionally pelagic' (taxa with asterisk) are included, the total number of pelagic species in Group A remains small (4.49\%), whereas that in Group B nearly doubles (47.10\%). The fact that even the conservative criterion for 'pelagic' I used shows such a large difference between the two groups clearly indicates that, whereas benthic lifestyles can be achieved with both body forms (Groups A and B), the body form of Group B has greater potential to be able to exploit pelagic, or more openwater, habitats through evolution by means of carangiform and thunniform swimming modes (see above). The predominantly benthic lifestyle of Group A sharks may be constrained by the anguilliform swimming mode (see above). The anguilliform swimming is said to be energetically more costly compared to carangiform and thunniform swimming (Webb, 1988), requiring them to rest on the seafloor more frequently-hence benthic. 


\section{EVOLUTIONARY IMPLICATIONS}

Sharks represent some of the oldest, yet one of the most diverse groups of vertebrates (Grogan et al., 2012). In both the fossil record (e.g., Maisey, 2012) and molecular studies (e.g., Naylor et al., 2012), modern sharks are classified into two superorders, Squalomorphii and Galeomorphii (Fig. 1A). Whereas many phylogenetic studies on extant elasmobranchs exist (Kitamura, 1996; Heinicke et al., 2009; Maisey et al., 2004; Human et al., 2006; Vélez-Zuazo \& Agnarsson, 2011; Pavan-Kumar et al., 2013; Amaral et al., 2018), Naylor et al.'s (2012) work remains to be the most extensive molecular-based (mitochondrial NADH 2 sequence) elasmobranch phylogeny based on 595 extant species. Below, I use Naylor et al.'s (2012) phylogenetic tree (Fig. 1A) to discuss the patterns and pathways of the body form evolution in sharks, and add further comments on the evolutionary implications. It should be noted that morphology-based phylogenetic studies of elasmobranchs (e.g., de Carvalho, 1996; Shirai, 1996) are deliberately avoided for discussion. This is because any discussion on the body forms using such trees would be circular arguments as characters to build those trees include variables related to body parts that constitute the body form in the first place.

My full body geometric morphometric analysis shows that phylogenetically the most basal as well as the two most derived squalomorph sharks - Hexanchiformes, Pristiophoriformes, and Squatiniformes (Fig. 7A) — fall in Group A (Fig. 4B). Other squalomorphs, notably squaliforms are found in Group B, whereas the two species of Echinorhiniformes arguably occur between the two major groups. These order-level taxonomic distributions suggest that shallowbodied forms (Group A) are plesiomorphic within Squalomorphii, that Squaliformes marks the evolution of deep-bodied forms (Group B), that Echinorhiniformes represents somewhat intermediate between Group A and Group B, and that the ultimate step in the body form evolution of Squalomorphii is marked by the dorsoventral flattening in Pristiophoriformes and 
Squatiniformes (Figs. 4A, B, 7A). On the other hand, phylogenetically the most basal order within Galeomorphii, Heterodontiformes, as well as a large number of the most derived galeomorphs, Lamniformes and non-scyliorhinid species of Carcharhiniformes, are found in Group B (Figs. 4A, B, 7A). The order that is arguably phylogenetically intermediate within Galeomorphii, orectolobiforms, and the basal group of Carcharhiniformes, scyliorhinid carcharhiniforms (see Naylor et al., 2012), belong to Group A (Fig. 7A).

If Naylor et al.'s (2012) phylogenetic tree, that has an identical order-level topology as da Cunha et al.'s (2017; except exclusion of Echinorhiniformes) tree, is used at face value, possible evolutionary patterns of body forms in Squalomorphii and Galeomorphii can be summarized as exactly opposite to one another where there are at least two possible scenarios (Fig. 7B). One scenario is to assume that Squalomorphii is fundamentally an assemblage of Group A sharks, but certain members, Squaliformes and Echinorhiniformes, independently evolved to become Group B sharks. Galeomorphii may be considered essentially as an assemblage of Group B shark, but eventually gave rise to two separate lineages of Group A sharks, Orectolobiformes and scyliorhinid Carcharhiniformes. In other words, the evolutionary shift in body forms in this first scenario is considered 'unidirectional' parallel evolution (Fig. 7B, top). The second scenario can be characterized as 'bidirectional' convergent evolution or evolutionary reversal (Fig. 7B, bottom). In this scenario, where the most basal squalomorph (Hexanchiformes) and galeomorph (Heterodontiformes) are nested within Group A and Group B, respectively, the next phylogenetically successive squalomorphs (Squaliformes and Echinorhiniformes) and galeomorphs (Orectolobiformes and scyliorhinid Carcharhiniformes) evolved to become, or at least showed a tendency towards becoming, Group B and Group A, respectively. The most derived squalomorphs (Pristiophoriformes and Squatiniformes) and galeomorph (Lamniformes 
and non-scyliorhinid Carcharhiniformes) then evolved to become Group A and Group B sharks, respectively. Furthermore, it is entirely possible that one of the two superorders could have undergone 'unidirectional' evolution and the other 'bidirectional.'

The possible scenarios shown in Figure 7 rely on the tree topology of each superorder attained by Naylor et al. (2012) that must be viewed with caution. Whereas some molecularbased phylogenetic analyses are regarded as not robust because of a small number of taxa examined (e.g., Kitamura, 1996; Human et al., 2006; Pavan-Kumar et al., 2013), practically all other molecular-based studies with a wide range of elasmobranch taxa yielded an identical tree topology for Galeomorphii as Naylor et al.'s (2012) tree (Fig. 1A) (Heinicke et al., 2009; Maisey et al., 2004; Amaral et al., 2018). Therefore, the two possible evolutionary pathways for Galeomorphii depicted in Figure 7 are equally plausible (but see below for further discussion). In practically all molecular-based analyses with a large number of taxa examined, Hexanchiformes is the basal-most Squalomorphii, but the exact phylogenetic interrelationship among the rest of the squalomorph orders remains to be tenuous. For example, Maisey et al. (2004, fig. 5A) and Heinicke et al. (2009, fig. 2) found the following topological arrangement: [Hexanchiformes + [Pristiophoriformes $+[$ Squaliformes $+[$ Echinorhiniformes + Squatiniformes $]]]]$. On the other hand, Amaral et al. 's (2018, fig. 5) study that did not include Echinorhiniformes yielded [Hexanchiformes $+[[$ Pristiophoriformes + Squaliformes $]+$ Squatiniformes $]]$. Vélez-Zuazo \& Agnarsson (2011, fig. 4) attained [Hexanchiformes + [Squaliformes $+[[$ Pristiophoriformes + Echinorhiniformes] + Squatiniformes]]], but we consider their work to be questionable because some taxa with overwhelming support for their monoplyly are shown to be non-monophyletic (e.g., Squaliformes, specifically Etmopteridae and Squatina, and Orectolobiformes). Nevertheless, whereas it is reasonable to assert that Hexanchiformes as a pioneer squalomorph 
taxon that belongs to Group A, the conflicting order-level tree topologies for the remaining squalomorphs make the evolutionary pathway suggested for Squalomorphii in Figure 7 less convincing. Regardless, in sharks as a whole, the body form evolution was clearly complex where each superorder (Squalomorphii and Galeomorphii) exploited both body form morphospaces through its phylogeny. The complex evolution of body forms in sharks is evident even if one maps Thomson \& Simanek's (1977) four body form groups (Fig. 1B) on the same phylogenetic tree, where the mapping (Fig. 7C) indicates that Group 1, 2, and 3 each evolved twice within the clade that consists of Orectolobiformes, Lamniformes, and Carcharhiniformes.

The earliest squalomorph as well as the earliest galeomorph are represented in the Early Jurassic record by Hexanchiformes and Heterodontiformes, respectively (Maisey, 2012), that is congruent with their basal-most position in the respective superorder suggested by molecularbased phylogenetic studies (Heinicke et al., 2009; Maisey et al., 2004; Naylor et al., 2012; Amaral et al., 2018; Fig. 1A). The fossil record indicates that, besides Hexanchiformes and Heterodontiformes, the major lineages of elasmobranchs had already become established by the Late Jurassic, at least including Squaliformes, Squatiniformes, Orectolobiformes, Lamniformes, and Carcharhiniformes (e.g., Kriwet \& Klug, 2004; Thies \& Leidner, 2011; Cappetta, 2012; Maisey, 2012). Although taxonomically not diverse, each of these shark orders has at least one representative taxon known by complete, articulated skeletal remains, some of which even preserve their body outline (Kriwet \& Klug, 2004; Thies \& Leidner, 2011). Although those fossil skeletons are two-dimensionally preserved taphonomically, many of the fossil taxa are reminiscent to their modern relatives in their respective order, suggesting that the body form diversity within each order has been relatively stable through geologic time. However, exceptions do exist. For example, a putative Late Jurassic lamniform, Palaeocarcharias stromeri 
de Beaumont, 1960, is interpreted to have had a relatively dorsoventrally flattened body suited for benthic lifestyle (Duffin, 1988; Cappetta, 2012), meaning that it likely represents a Group A shark unlike any other lamniforms examined in my study. In addition, the vast majority of fossil sharks are known only from their teeth (Cappetta, 2012; Maisey, 2012) where their body forms can only be speculated. In addition, there are even many extinct clades not represented in the modern shark lineages, including an extinct shark order Synechodontiformes (e.g., Kriwet \& Klug, 2004; Thies \& Leidner, 2011; Cappetta, 2012). The fact that exceptions and extinct forms exist strongly suggests that the actual evolutionary pathways in each superorder must have been even more complex than either scenario depicted in Figure 7.

The clade that unites Squalomorphii and Galeomorphii is the basal-most Selachii (Fig. 1A), but whether the earliest shark was a Group A shark or a Group B shark is uncertain. However, the fact that the earliest batoids (skates and rays) are also known from Early Jurassic rocks (Cappetta, 2012; Maisey, 2012) and that Batoidea is sister to Selachii (Fig. 1A) suggests that the earliest shark could have had a shallow body depth. If so, it is reasonable to postulate a hypothesis that the earliest shark was possibly a Group A shark.

\section{CONCLUSIONS}

Sharks have a long geologic history (Grogan et al., 2012; Maisey, 2012) in which their success has been attributed to their diversity in body shape and locomotor design (Lauder \& Di Santo, 2016). Traditionally, sharks were classified into four groups according to their basic body forms (Thomson \& Simanek, 1977), but the proposition was based only on 56 species using simple morphometric analysis. In my study, I examined the body forms of nearly all the known (ca. 
470) extant shark species illustrated in the shark field guide, Sharks of the World: A Fully

Illustrated Guide by Ebert et al. (2013). I used landmark-based geometric morphometrics, and I ran three different analyses: the 'full body,' 'precaudal body,' and 'caudal fin' analyses.

Although there are some indications that the body size and taxonomic order may have some effects on the overall body shape variation, the results of my full body analysis strongly suggest that there are two major body forms in sharks, rather than four. The two major body form divisions are characterized as a 'shallow-bodied' form (Group A) and 'deep-bodied' form (Group B). This pattern is also present in the precaudal body analysis, because there were also two major divisions. In contrast, the caudal fin analysis indicated no major plot divisions, implying that all sharks share essentially one basic caudal fin design. However, it is noteworthy that sharks of Thomson \& Simanek's (1977) Groups 1, 2, and 4 as well as some Group 3 are found to occupy different regions within the Group B morphospace, whereas the remaining sharks of Group 3 represent my Group A sharks. If distinctively dorsoventrally flattened pristiophoriform and squatiniform sharks are considered to be an additional category, this observation would mean that there may be arguably as many as six subcategories of body forms in sharks. However, decisively separating among the six subcategories is not possible from my data, because their morphospaces in part overlap one another within each of my two major groups.

Based on my geometric morphometric analyses, particularly the results from the full body analysis that shows two major body forms in sharks, I made inferences about the functional, ecological and evolutionary implications. First, I found that swimming modes in sharks are highly correlated with body forms. For example, Group A sharks are predominantly anguilliform swimmers whereas Group B sharks are represented by carangiform and thunniform 
swimmers. Second, the majority of Group A sharks are found to be benthic, whereas pelagic forms are relatively common among Group B sharks. Third, based on the known fossil record as well as previously published molecular-based phylogenetic trees, each of the two superorders of sharks, Squalomorphii and Galeomorphii, must have gone through complex evolutionary history. This proposition is because each superorder contains both Group A and Group B sharks, possibly involving parallel evolution from one group to the other or at least one episode of evolutionary reversal. Lastly, the most ancestral shark, the clade that unites Squalomorphii and Galeomorphii, was possibly a benthic form with a Group A body form.

This study represents the most comprehensive investigation of the body forms in sharks since Thomson \& Simanek's (1977) work. However, it is important to emphasize that conclusions drawn from my data must be viewed as working hypotheses because of the limitations that were imposed to my geometric morphometric analyses where the threedimensionality as well as certain anatomical parts (the second dorsal and anal fins as well as the caudal fluke) could not be captured in my data (see Materials and Methods). It may be potentially fruitful to investigate the overall head and body shapes not only based on a twodimensional geometric morphometrics on their dorsoventral aspect (that would also capture the caudal fluke), but also using three-dimensional geometric morphometrics. Such analyses may allow one to tease out any additional morphological differences or even potentially different groupings of body forms in sharks in which my study could not elucidate.

By building on Thomson \& Simanek's (1977) conceptual framework, the results of this study provides a fresh look at the body form diversity in sharks. To elucidate further the functional, ecological, and evolutionary implications of the two identified major body forms in sharks, it may be worth to collect the first occurrence data of each major lineage of sharks in the 
geologic record. Such data may help to examine whether or not a certain 'cross-over' event from one body form group to the other body form group would correspond to any major geologic event or environmental shift. A morphometric investigation of the body form of extinct sharks, including completely extinct lineages where their skeletons and body outlines are known (e.g., Synechodontiformes) may also shed additional insights into the evolution of the body form diversity patterns.

Thomson \& Simanek (1977) used a relatively comprehensive guidebook of sharks available to them at that time (i.e., Bigelow \& Schroeder, 1948). I applied the same strategy by using a quite comprehensive guidebook of extant sharks (i.e., Ebert et al., 2013) and a more rigorous technique, landmark-based geometric morphometrics. My study demonstrates that such a use of an identification guidebook, especially if illustrations are given in a uniform manner, can be a powerful tool for the field of comparative anatomy to investigate a wide morphological spectrum of a given set of organisms. 


\section{REFERENCES}

Alexander RM. 1965. The lift produced by the heterocercal tail of Selachii. Journal of Experimental Biology 43: 131-138.

Amaral CRL, Pereira F, Silva DA, Amorim A, de Carvalho E. F. 2018. The mitogenomic phylogeny of Elasmobranchii (Chondrichthyes). Mitochondrial DNA Part A 29: 867878.

Bigelow HB, Schroeder WC. 1948. The fishes of the western North Atlantic. No. 1, Part 1. Lancelets, Cyclostomes and Sharks. New Haven: Sears Foundation Press.

Blake RW. 2004. Fish functional design and swimming performance. Journal of Fish Biology 65: $1193-1222$.

Breder CM. 1926. The locomotion of fishes. Zoologica 4: 159-257.

Cappetta H. 2012. Chondrichthyes. Mesozoic and Cenozoic Elasmobranchii: teeth. In: Schultze H-P, ed. Handbook of paleoichthyology, volume 3E. München: Verlag Dr. Friedrich Pfeil, 1-512.

Compagno LJV. 1984. FAO species catalogue. Vol. 4: sharks of the world, part 1 Hexanchiformes to Lamniformes. FAO Fisheries Synopsis No. 125 4: 1-250.

Compagno LJV. 1990. Alternative life-history styles of cartilaginous fishes in time and space. Environmental Biology of Fishes 28: 33-75.

Compagno LJV. 2002. FAO species catalogue. Vol. 2: sharks of the world, bullhead, mackerel and carpet sharks (Heterodontiformes, Lamniformes and Orectolobiformes). FAO Species Catalogue for Fishery Purposes No. 1 2: 1-250.

Compagno LJV, Fowler S, Dando M. 2005. A field guide to the sharks of the world. London: Harper Collins. 
da Cunha DB, da Silva Rodrigues-Filho LF, de Luna Sales JB. 2017. A review of the mitogenomic phylogeny of the Chondrichthyes. IntechOpen Chapter 6: 113-126.

de Beaumont G. 1960. Observations préliminaires sur trois Sélaciens nouveaux du calcaire lithographique d'Eichstätt (Bavière). Eclogae Geologicae Hevetiae 53: 315-328.

de Carvalho MR. 1996. Higher-level elasmobranch phylogeny, basal squaleans, and paraphyly. In: Stiassny MLJ, Parenti LR, Johnson GD, eds. Interrelationships of fishes. San Diego: Academic Press, 35-62.

Duffin C. 1988. The Upper Jurassic selachian Palaeocarcharias de Beaumont (1960). Zoological Journal of the Linnean Society 94: 271-286.

Dulvy NK, Fowler SL, Musick JA, Cavanagh RD, Kyne PM, Harrison LR, Carlson JK, Davidson LNK, Fordham SV, Francis MP, Pollock CM, Simpfendorfer CA, Burgess GH, Carpenter KE, Compagno LJV, Ebert DA, Gibson C, Heupel MR, Livingstone SR, Sanciangco JC, Stevens JD, Valenti S, White WT. 2014. Extinction risk and conservation of the world's sharks and rays. eLife 3: e00590.

Ebert DA, Fowler S, Compagno L, Dando M. 2013. Sharks of the world: a fully illustrated guide. Plymouth: Wild Nature Press.

Fu AL, Hammerschlag N, Lauder GV, Wilga CD, Kuo C, Irschick DJ. 2016. Ontogeny of head and caudal fin shape of an apex marine predator: the tiger shark (Galeocerdo Cuvier). Journal of Morphology 277: 556-564.

Garrick JAF, Springer S. 1964. Isistius plutodus, a new squaloid shark from the Gulf of Mexico. Copeia 1964 4: 678-682. 
Glenn CL, Mathias JA. 1987. Body shrinkage in young walleye, Stizostedion vitreum, preserved with AFA, formalin, ethanol, and quick freezing. Canadian Field-Naturalist 101: $408-414$.

Gray J. 1933. Studies in animal locomotion. I. the movement of fish with special reference to the eel. Journal of Experimental Biology 10: 88-104.

Grogan ED, Lund R, Greenfest-Allen E. 2012. The origin and relationships of early chondrichthyans. In: Carrier JC, Musick JA, Heithaus MR, eds. Biology of sharks and their relatives, 2nd edn. Boca Raton: CRC Press, 3-30.

Heinicke MP, Naylor GJP, Hedges SB. 2009. Cartilaginous fishes (Chondrichthyes). In: Hedges SB, Kumar S, eds. The timetree of life. United Kingdom: Oxford University Press, 320-327.

Hermann J. 1783. Helminthologische bemerkungen. Naturforscher 19: 31-59.

Human BA, Owen EP, Compagno LJV, Harley EH. 2006. Testing morphologically based phylogenetic theories with the cartilaginous fishes with molecular data, with special reference to the catshark family (Chondrichthyes; Scyliorhinidae) and the interrelationships within them. Molecular Phylogenetics and Evolution 39: 384-391.

Iosilevskii G, Papastamatiou YP. 2016. Relations between morphology, buoyancy and energetics of requiem sharks. Royal Society Open Science 3: 160406.

Irschick DJ, Hammerschlag N. 2014. Morphological scaling of body form in four shark species differing in ecology and life history. Biological Journal of the Linnean Society 114: 126135. 
Irschick DJ, Fu A, Lauder G, Wilga C, Kuo C, Hammerschlag N. 2017. A comparative morphological analysis of body and fin shape for eight shark species. Biological Journal of the Linnean Society 122: 589-604.

Jawad LA. 2013. Book review: sharks of the world: a fully illustrated guide. Journal of Fish Biology 83: 1487-1488.

Kitamura T. 1996. Analysis of mitochondrial DNA sequence in elasmobranchs. Kaiyo Monthly 28: $354-359$.

Klingenberg CP. 2011. MorphoJ: An integrated software package for geometric morphometrics. Molecular Ecology Resources 11: 353-357.

Klingenberg CP. 2016. Size, shape, and form: a concept of allometry in geometric morphometrics. Development Genes and Evolution 226: 113-137.

Kolbe JK, Leal M, Shoener TW, Spiller DA, Losos JB. 2012. Founder effect persist despite adaptive differentiation: A field experiment with lizards. Science 335: 1086-1089.

Kriwet J, Klug S. 2004. Late Jurassic selachians (Chondrichthyes, Elasmobranchii) from southern Germany: re-evaluation on taxonomy and diversity. Zitteliana 44: 67-95.

Lauder GV, Di Santo V. 2016. Swimming mechanics and energetics of elasmobranch fishes. In: Shadwick RE, Farrell AP, Brauner CJ, eds. Physiology of elasmobranch fishes: structure and environment. San Diego: Academic Press, 219-253.

Lauder GV, Huey RB, Monson RK, Jensen RJ. 1995. Systematics and the study of organismal form and function. BioScience 45: 696-704.

Lighthill MJ. 1975. Mathematical biofluidynamics. Cambridge: Cambridge Press.

Lindsey CC. 1978. Form, function, and locomotory habits in fish. In: Hoar WS, Randall DJ, eds. Fish physiology vol. 7 locomotion. New York: Academic Press, 1-100. 
Lingham-Soliar T. 2005. Caudal fin allometry in the white shark Carcharodon carcharias: Implications for locomotory performance and ecology. Naturwissenschaften 92: 231236.

Linnaeus C. 1758. Systema naturae per regna tria naturae. vol. 1. Regnum animale, 10th edn. Stockholm: Laurentii Salvii.

Losos JB. 1990. The evolution of form and function: morphology and locomotor performance in West Indian Anolis lizards. Evolution 44: 1189-1203.

Maia A, Wilga CA. 2016. Dorsal fin function in spiny dogfish during steady swimming. Journal of Zoology 298: 139-149.

Maia AMR, Wilga CAD, Lauder GV. 2012. Biomechanics of locomotion in sharks, rays, and chimaeras. In: Carrier JC, Musick JA, Heithaus MR, eds. Biology of sharks and their relatives, 2nd edn. Boca Raton: CRC Press, 125-151.

Maisey JG. 2012. What is an 'elasmobranch'? The impact of paleontology in understanding elasmobranch phylogeny and evolution. Journal of Fish Biology 80: 918-951.

Maisey JG, Naylor GJ, Ward DJ. 2004. Mesozoic elasmobranchs, neoselachian phylogeny, and the rise of modern elasmobranch diversity. In: Arratia G, Tintori A, eds. Mesozoic fishes III-systematics, paleoenvironments and biodiversity. München: Verlag Dr. Friedrich Pfeil, 17-56.

Meng QW, Chu YD, Li S. 1985. A new species of Dalatiidae (Squaliformes) of China. Acta Zootaxonomica Sinica 10: 442-444.

Mitteroecker P, Gunz P. 2009. Advances in geometric morphometrics. Evolutionary Biology 36: $235-247$. 
Motta PJ, Huber DR. 2012. Prey capture behavior and feeding mechanics of elasmobranchs. In: Carrier JC, Musick JA, Heithaus MR, eds. Biology of sharks and their relatives, 2nd edn. Boca Raton: CRC Press, 153-209.

Müller J, Henle FGJ. 1838. On the generic characters of cartilaginous fishes, with descriptions of new genera. Magazine of natural history and journal of zoology, botany, mineralogy, geology and meteorology 2: 33-37, 88-91.

Naylor GJP, Caira JN, Jensen K, Rosana KAM, Straube N, Lakner C. 2012. Elasmobranch phylogeny: a mitochondrial estimate based on 595 species. In: Carrier JC, Musick JA, Heithaus MR, eds. Biology of sharks and their relatives, 2nd edn. Boca Raton: CRC Press, 31-56.

\section{Pavan-Kumar A, Gireesh-Babu P, Babu PP, Jaiswar AK, Hari Krishna V, Prasasd KP, Chaudharia A, Raje SG, Chakraborty SK, Krishna G, Lakra WS. 2013. Molecular phylogeny of elasmobranchs inferred from mitochondrial and nuclear markers. Molecular Biology Reports 41: 447-457.}

Quoy JRC, Gaimard JP. 1824. Description des poissons, chapître IX. In: Freycinet L, ed. Voyage autour du Monde...exécuté sur les corvettes de L. M. "L'Uranie" et "La Physicienne," pendant les années 1817, 1818, 1819 et 1820. Paris, 1-328.

R Core Team. 2016. $R$ : a language and environment for statistical computing. Vienna: $\mathrm{R}$ Foundation for Statistical Computing.

Reiss KL, Bonnan MF. 2010. Ontogenetic scaling of caudal fin shape in Squalas acanthias (Chondrichthyes, Elasmobranchii): a geometric morphometric analysis with implications for caudal fin functional morphology. Anatomical Record 293: 1184-1191.

Rohlf FJ. 2015. The tps series of software. Hystrix, the Italian Journal of Mammalogy 26: 9-12. 
Rohlf FJ, Marcus LF. 1993. A revolution in morphometrics. Trends in Ecology and Evolution 8: 129-132.

Russell ES. 1916. Form and function: a contribution to the history of animal morphology. Chicago: University of Chicago Press.

Scacco U, La Mesa G, Vacchi M. 2010. Body morphometrics, swimming diversity and niche in demersal sharks: a comparative case study from the Mediterranean Sea. Scientia Marina 74: 37-53.

Sfakiotakis MD, Lane M, Davies JB. 1999. Review of fish swimming modes for aquatic locomotion. IEEE Journal of Oceanic Engineering 24: 237-252.

Shadwick RE, Goldbogen JA. 2012. Muscle function and swimming in sharks. Journal of Fish Biology 80: 1904-1939.

Shirai S. 1996. Phylogenetic interrelationships of neoselachians (Chondrichthyes: Euselachii). In: Stiassny MLJ, Parenti LR, Johnson GD, eds. Interrelationships of fishes. San Diego: Academic Press, 9-34.

Smith A. 1829. Contributions of the natural history of South Africa. Zoological Journal 4: 433444.

Thies D, Leidner A. 2011. Sharks and guitarfishes (Elasmobranchii) from the Late Jurassic of Europe. Palaeodiversity 4: 63-184.

Thomson KS. 1976. On the heterocercal tail in sharks. Paleobiology 2: 19-38.

Thomson KS, Simanek DE. 1977. Body form and locomotion in sharks. American Zoologist 17: $343-354$.

Vélez-Zuazo X, Agnarsson I. 2011. Shark tales: a molecular species-level phylogeny of sharks (Selachimorpha, Chondrichthyes). Molecular Phylogenetics and Evolution 58: 207-217. 
Webb PW. 1984. Body form, locomotion and foraging in aquatic vertebrates. American Zoologist 24: 107-120.

Webb PW. 1988. Simple physical properties and vertebrate aquatic locomotion. American Zoologist 28: 709-725.

Weigmann S. 2016. Annotated checklist of the living sharks, batoid and chimaeras (Chondrichthyes) of the world, with a focus on biogeographical diversity. Journal of Fish Biology 88: 837-1037.

Weihs D. 1989. Design feature and mechanics of axial locomotion in fish. American Zoologist 29: 151-160.

White WT, Kyne PM, Harris M. 2019. Lost before found: a new species of whaler shark Carcharhinus obsolerus from the Western Central Pacific known only form historic records. PLoS ONE 14: e0209387.

Wilga CD, Lauder GV. 2002. Function of the heterocercal tail in sharks: quantitative wake dynamics during steady horizontal swimming and vertical maneuvering. Journal of Experimental Biology 205: 2365-2374.

Zelditch ML, Swiderski DL, Sheets HD. 2012. Geometric morphometrics for biologists: a primer, 2nd edn. London: Academic Press. 
Table 1. Genera of Group A and B sharks (see Fig. 4B) and their taxonomic order (CAR, Carcharhiniformes; ECH, Echinorhiniformes; HET, Heterodontiformes; HEX, Hexanchiformes; LAM, Lamniformes; ORE, Orectolobiformes; PRI, Pristiophoriformes; SQL, Squaliformes; SQT, Squatiniformes), families, and total numbers of species in parentheses. Superscripts indicate swimming modes assigned by Maia et al. (2012) (1, anguilliform; 2, carangiform; 3, thunniform: see text). Genera in bold are taxa identified as 'pelagic,' and genera with asterisk (*) represent benthic taxa that are occasionally pelagic (see text). In this table, all known extant species of Squatiniformes (Squatina) are counted.

Group A (44 genera; 245 species)

Apristurus (CAR: Scyliorhinidae; 35) ${ }^{1}$

Asymbolus (CAR: Scyliorhinidae; 9) ${ }^{1}$

Atelomycterus (CAR: Scyliorhinidae; 5$)^{1}$

Aulohalaelurus (CAR: Scyliorhinidae; 2$)^{1}$

Brachaelurus (ORE: Brachaeularidae; 2) ${ }^{1}$

Bythaelurus (CAR: Scyliorhinidae; 8$)^{1}$

Cephaloscyllium (CAR: Scyliorhinidae; 21$)^{1}$

Cephalurus (CAR: Scyliorhinidae; 1$)^{1}$

Chiloscyllium (ORE: Hemiscylliidae; 7) ${ }^{1}$

*Chlamydoselachus (HEX: Chlamydosechalid.; 2) ${ }^{1}$

Cirrhoscyllium (ORE: Parascylliidae; 3$)^{1}$

Ctenacis (CAR: Proscylliidae; 1$)^{1}$

*Echinorhinus (ECH: Echinorhinidae; 2)

Eridacnis (CAR: Proscylliidae; 3$)^{1}$

Eucrossorhinus (ORE: Orectolobidae; 1$)^{1}$

Figaro (CAR: Scyliorhinidae; 2$)^{1}$

Galeus (CAR: Scyliorhinidae; 17) ${ }^{1}$

Ginglymostoma (ORE: Ginglymostomatidae; 1$)^{1}$

Gollum (CAR: Pseudotriakidae; 3$)^{1}$

Halaelurus (CAR: Scyliorhinidae; 7) ${ }^{1}$

Haploblepharus (CAR: Scyliorhinidae; 9) ${ }^{1}$

Hemiscyllium (ORE: Hemiscylliidae; 8$)^{1}$

Heptranchias (HEX: Hexanchidae; 1$)^{1}$

Hexanchus (HEX: Hexanchidae; 2$)^{1}$

Holohalaelurus (CAR: Scyliorhinidae; 5) ${ }^{1}$

Isistius (SQL: Dalatiidae; 3$)^{2}$

Nebrius (ORE: Ginglymostomatidae; 1$)^{1}$

Notorynchus (HEX: Hexanchidae; 1$)^{1}$

Orectolobus (ORE: Orectolobidae; 10) ${ }^{1}$

Parascyllium (ORE: Parascylliidae; 5$)^{1}$

Parmaturus (CAR: Scyliorhinidae; 9) ${ }^{1}$

Pilotrema (PRI: Pristiophoridae; 1)

Planonasus (CAR: Pseudotriakidae; 1$)^{1}$

Poroderma (CAR: Scyliorhinidae; 2$)^{1}$
Group B (60 genera; 259 species)

Aculeola (SQL: Etompteridae; 1) ${ }^{2}$

Carcharhinus (CAR: Carcharhinidae; 32) ${ }^{2}$

Carcharias (LAM: Odontaspididae; 1$)^{2}$

Carcharodon (LAM: Lamnidae; 1$)^{3}$

*Centrophorus (SQL: Centrophoridae; 13) ${ }^{2}$

Centroselachus (SQL: Somniosidae; 1$)^{2}$

Centroscyllium (SQL: Etompteridae; 7) ${ }^{2}$

Centroscymnus (SQL: Somniosidae; 2$)^{2}$

Cetorhinus (LAM: Cetorhinidae; 1)

Chaenogaleus (CAR: Hemigaleidae; 1)

Cirrhagaleus (SQL: Squalidae; 3) ${ }^{2}$

Dalatias (SQL: Dalatiidae; 1$)^{2}$

Deania (SQL: Centrophoridae; 4$)^{2}$

*Etmopterus (SQL: Etompteridae; 37$)^{2}$

*Euprotomicroides (SQL: Dalatiidae; 1$)^{2}$

Euprotomicrus (SQL: Dalatiidae; 1$)^{2}$

Eusphyra (CAR: Sphyrnidae; 1) ${ }^{2}$

Furgaleus (CAR: Triakidae; 1)

Galeocerdo (CAR: Carcharhinidae; 1$)^{2}$

Galeorhinus (CAR: Triakidae; 1)

Glyphis (CAR: Carcharhinidae; 5) ${ }^{2}$

Gogolia (CAR: Triakidae; 1)

Hemigaleus (CAR: Hemigaleidae; 2)

Hemipristis (CAR: Hemigaleidae; 1)

Hemitriakis (CAR: Triakidae; 7)

Heterodontus (HET: Heterodontidae; 9)

Heteroscymonoides (SQL: Dalatiidae; 1)

Hypogaleus (CAR: Triakidae; 1)

Iago (CAR: Triakidae; 3)

Isogomphodon (CAR: Carcharhinidae; 1$)^{2}$

Isurus (LAM: Lamnidae; 2$)^{3}$

Lamiopsis (CAR: Carcharhinidae; 1$)^{2}$

Lamiospsis (CAR: Carcharhinidae; 1$)^{2}$

Lamna (LAM: Lamnidae; 2$)^{3}$ 
Pristiophorus (PRI: Pristiophoridae; 7)

Proscyllium (CAR: Proscylliidae; 2$)^{1}$

Pseudoginglymostoma (ORE: Ginglymostomat.;1)

Pseudotriakis (CAR: Pseudotrakidae; 1$)^{1}$

Schroederichthys (CAR: Scyliorhinidae; 5) ${ }^{1}$

Scyliorhinus (CAR: Scyliorhinidae; 15) ${ }^{1}$

Squaliolus (SQL: Dalatiidae; 2)

Squatina (SQT: Squatinidae; 20)

Stegostoma (ORE: Stegostomatidae; 1)

Sutorectus (ORE: Orectolobidae; 1$)^{1}$
Leptocharias (CAR: Leptochariidae; 1)

Megachasma (LAM: Megachasmidae; 1)

Mitsukurina (LAM: Mitsukurinidae; 1)

Mollisquama (SQL: Dalatiidae; 1$)^{2}$

Mustelus (CAR: Triakidae; 27)

Nasolamia (CAR: Carcharhinidae; 1$)^{2}$

Negaprion (CAR: Carcharhinidae; 2$)^{2}$

Odontaspis (LAM: Odontaspididae; 2)

Oxynotus (SQL: Oxynotidae; 5) ${ }^{2}$

Paragaleus (CAR: Hemigaleidae; 4)

Prionace (CAR: Carcharhinidae; 1) ${ }^{2}$

Proscymnodon (SQL: Somniosidae; 2$)^{2}$

Pseudocarcharias (LAM:Pseudocarchar.; 1)

Rhincodon (ORE: Rhincodontidae; 1)

Rhizoprionodon (CAR: Carcharhinidae; 7) ${ }^{2}$

Scoliodon (CAR: Carcharhinidae; 2)

Scylliogaleus (CAR: Triakidae; 1)

Scymnodon (SQL: Somniosidae; 1$)^{2}$

Scymnodalatias (SQL: Somniosidae; 4$)^{2}$

Somniosus (SQL: Somniosidae; 5) ${ }^{2}$

Sphyrna (CAR: Sphyrnidae; 7) ${ }^{2}$

Squalus (SQL: Squalidae; 25) ${ }^{2}$

*Triakis (CAR: Triakidae; 5)

Trianodon (CAR: Carcharhinidae; 1$)^{2}$

Trigonognathus (SQL: Etompteridae; 1) ${ }^{2}$

Zameus (SQL: Somniosidae; 2$)^{2}$ 
Chondrichthyes

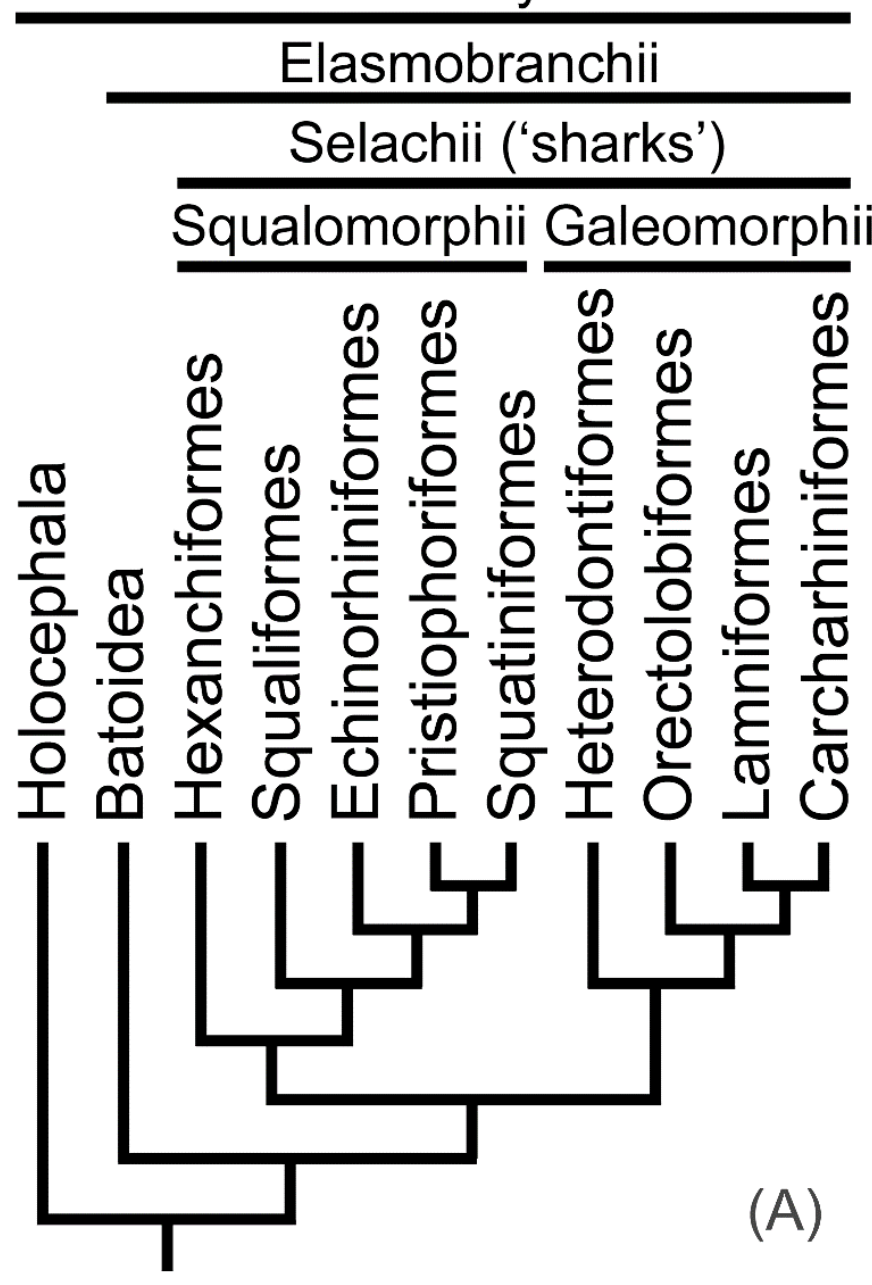

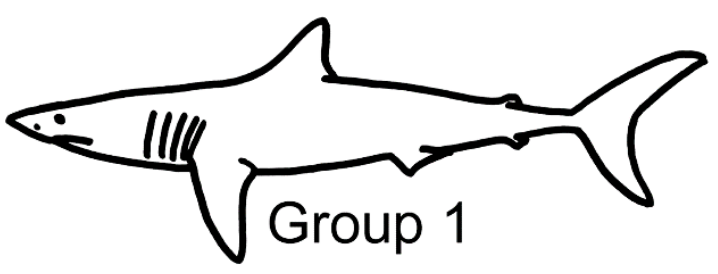
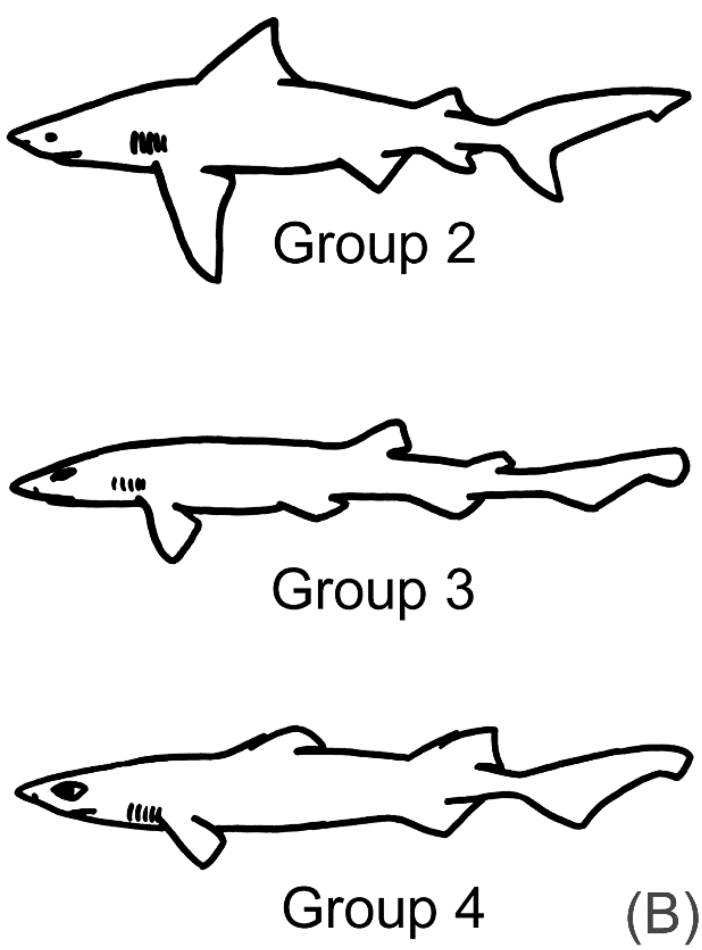

Figure 1. A, Molecular-based phylogeny of Chondrichthyes showing systematic position and interrelationships of shark orders (after Naylor et al., 2012). B, Thomson \& Simanek's (1977) four groups of shark body forms (representative genera: Carcharodon, Cetorhinus, Isurus, Lamna and Rhincodon for Group 1; representative genera: Alopias, Aprionodon, Carcharias, Carcharhinus, Galeocerdo, Hypoprion, Negaprion, Paragaleus, Prionace, Scoliodon and Sphyrna for Group 2; representative genera: Aspristurus, Galeus, Ginglymostoma, Mustelus, Pseudotriakis, Scyliorhinus and Triakis for Group 3; representative genera: Centroscyllium, Centroscymnus, Dalatias, Echinorhinus, Etmopterus, Isistius, Somniosus and Squalus for Group 4). 

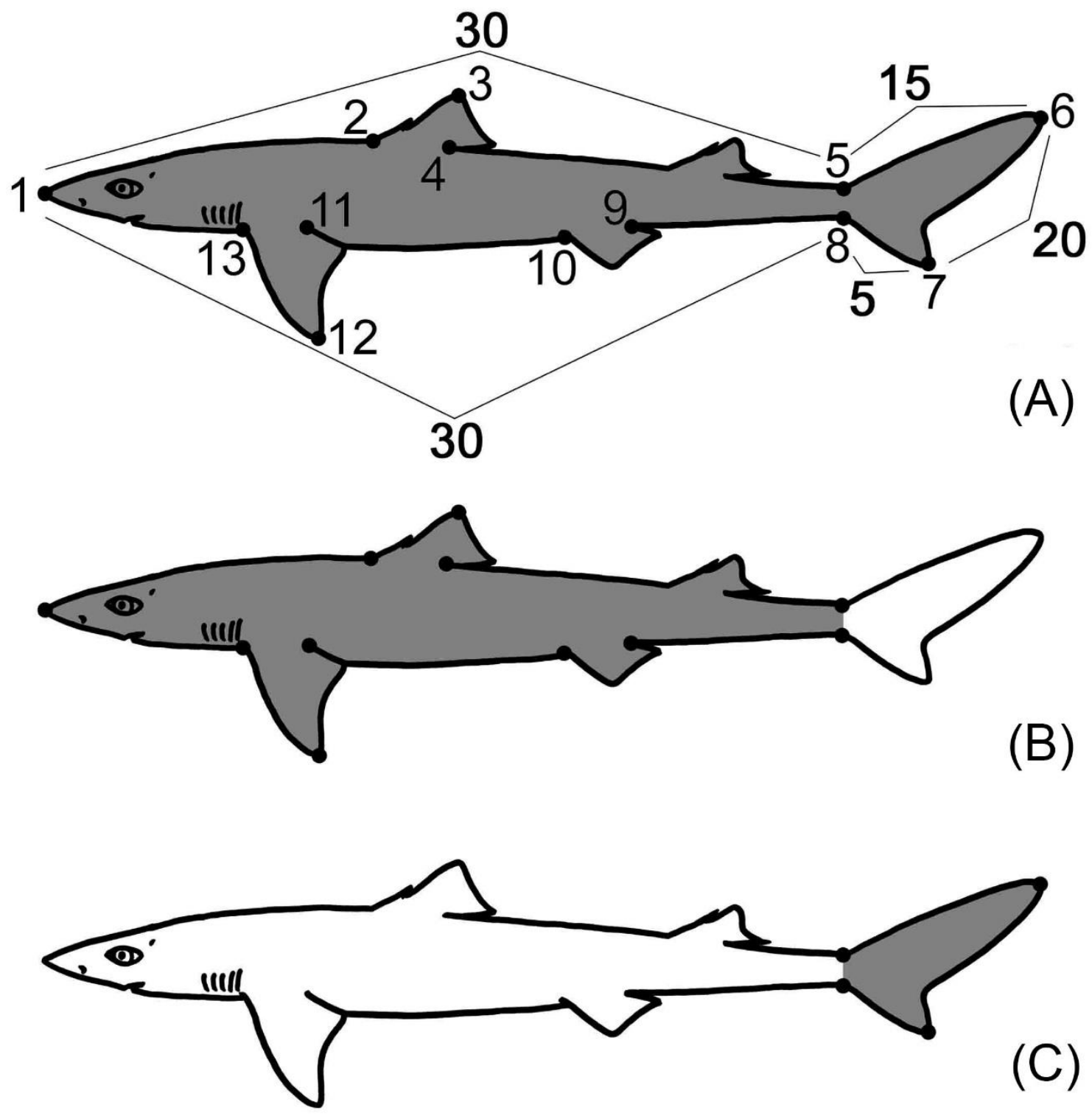

Figure 2. Homologous landmarks (circles) and non-homologous semi-landmarks (each bracket with total plot number within the range in bold: see text) used for morphometric analyses in this study (drawing of Squalus acanthias as an example: after Ebert et al., 2013, p. 83; not to scale). A, 'Full body analysis' showing 13 homologous landmarks (1, tip of the snout; 2, dorsal fin origin; 3, dorsal fin apex; 4, dorsal fin insertion; 5, caudal fin upper origin; 6, posterior tip of dorsal lobe; 7, ventral tip of ventral lobe; 8 , lower origin of caudal fin; 9 , pelvic fin insertion; 10 , pelvic fin origin; 11, pectoral fin insertion; 12, pectoral fin apex; 13, pectoral fin origin). B, 'Precaudal body analysis' showing 11 of 13 homologous landmarks along with total of 60 (= 30 + 30) non-homologous semi-landmarks (see Fig. 2A) used. C, 'Caudal fin analysis' showing four of 13 homologous landmarks along with total of $40(=15+20+5)$ non-homologous semilandmarks (see Fig. 2A) used. 


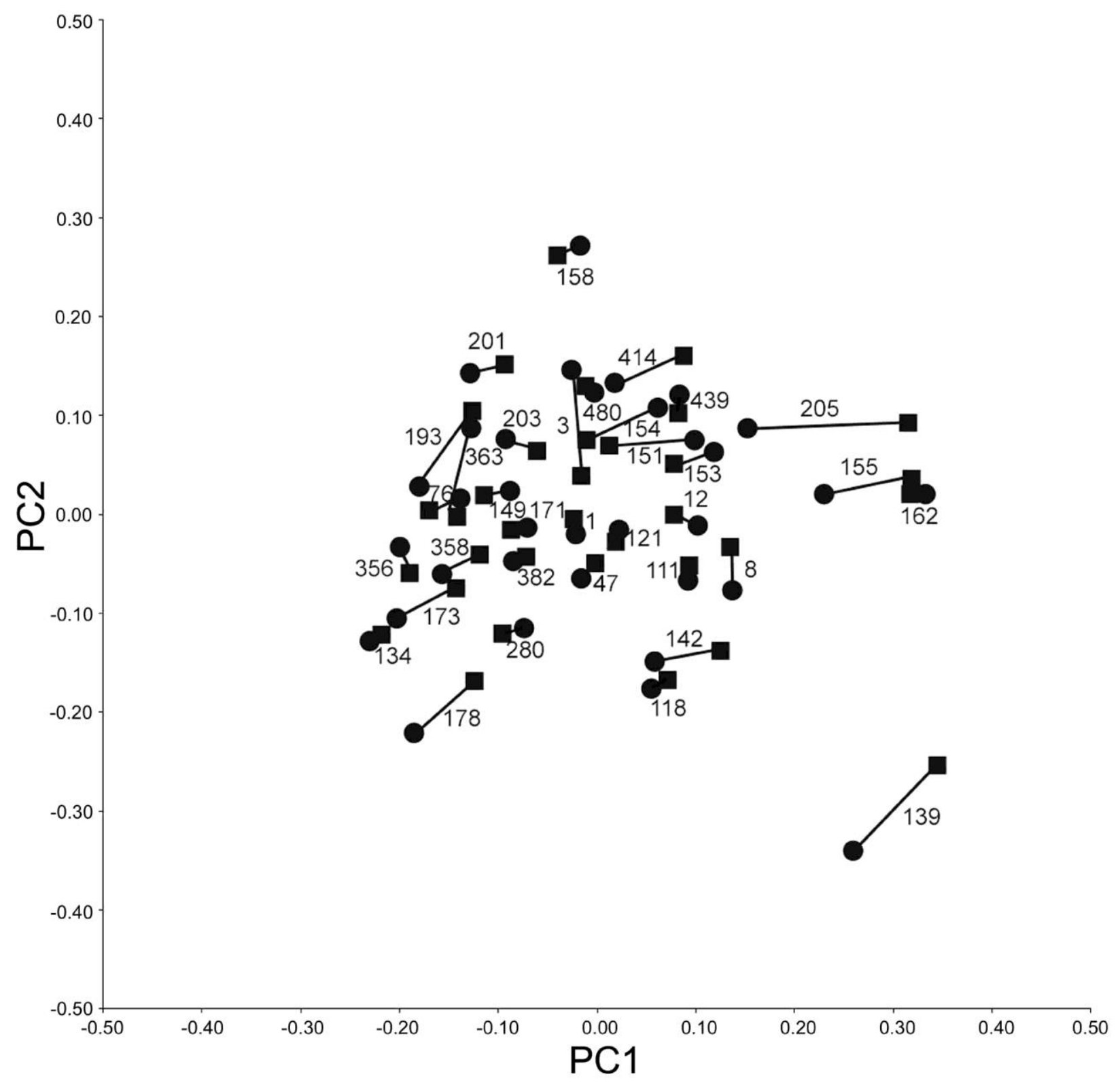

Figure 3. Pilot study of caudal fin shapes in one representative shark species of each shark family (see text), demonstrating similarity between Ebert et al.'s (2013) book illustrations (squares) and caudal fins directly traced from museum specimens (circles; see Appendix 2). Number indicates species code (see Appendix 1) with line connecting Ebert et al.'s (2013) illustration and museum specimen for each examined species. 

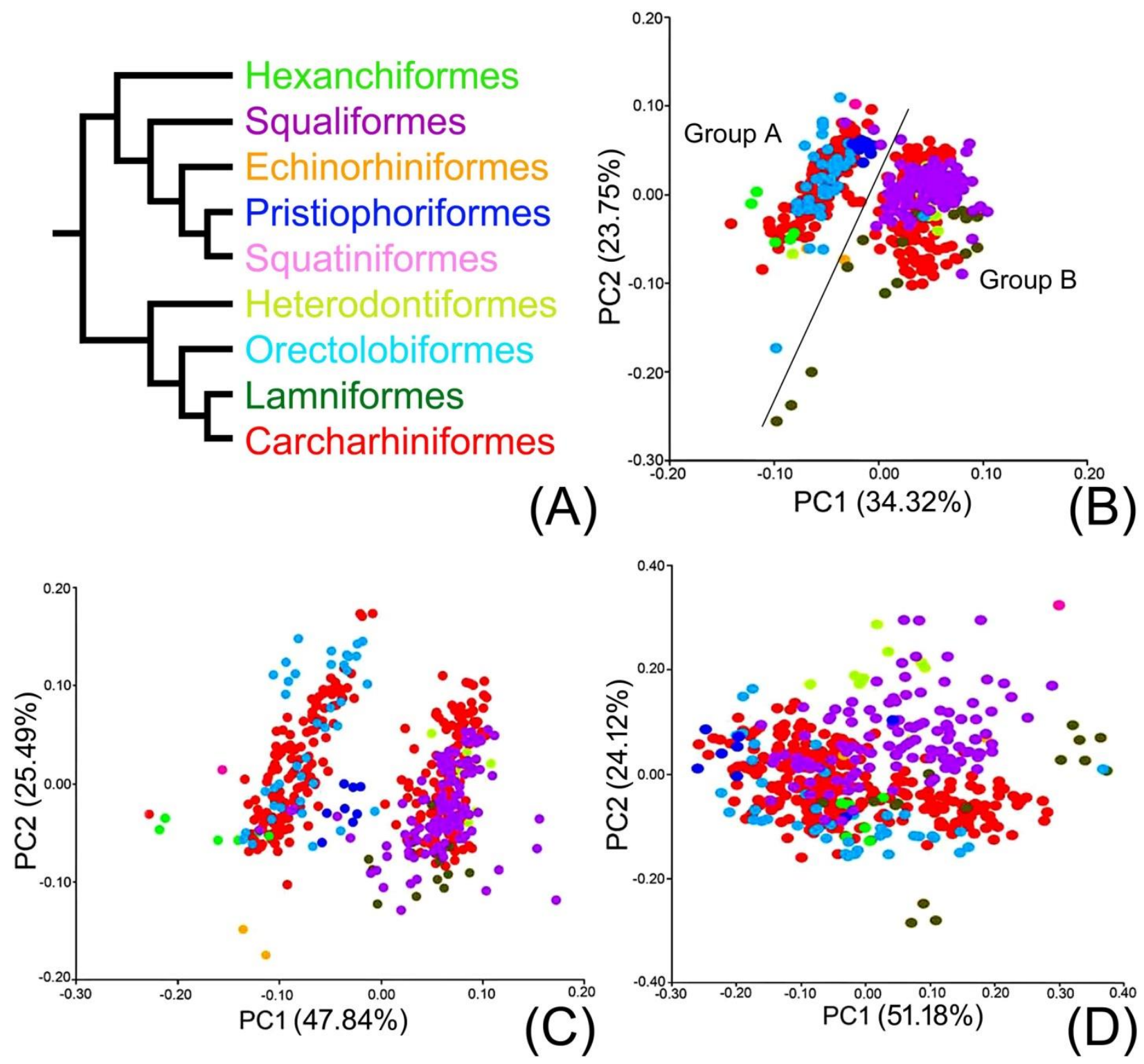

Figure 4. A, Phylogenetic tree of shark orders (after Naylor et al., 2012) showing color-coding scheme of taxonomic orders used for plots in Fig. 4B-D. B, Scatter plot diagram of full body analysis showing division (line) between Group A and Group B discussed in this paper. C, Scatter plot diagram of precaudal body analysis. D, Scatter plot diagram of caudal fin analysis. Percentage in parentheses in each axis denotes percent variation explained by that principle component. 

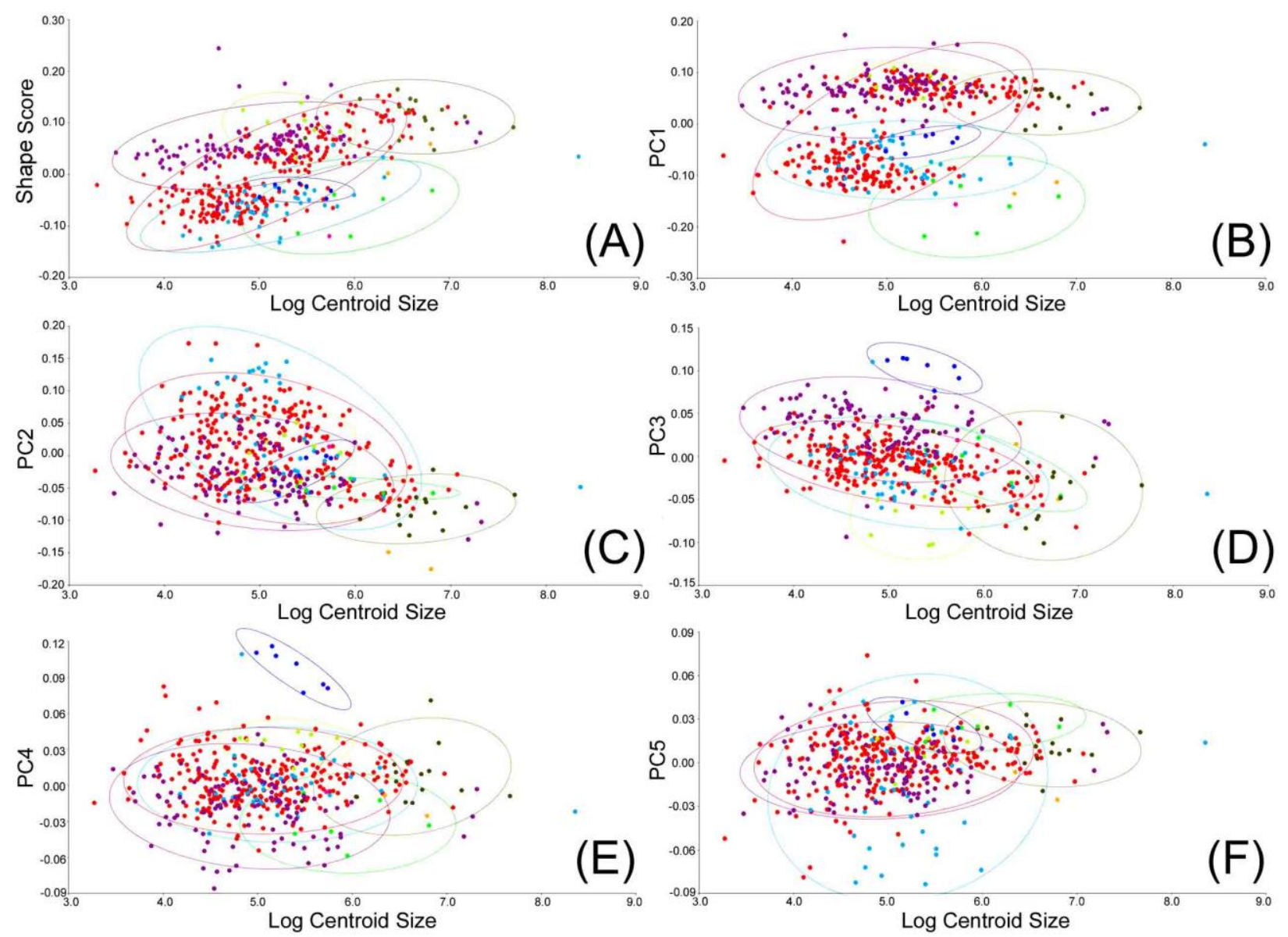

Figure 5. Scatter plot diagrams between log centroid size $(x)$ and shape score $(y)$ of precaudal body for 471 species of sharks examined (see Fig. 4A for color codes). A, Log centroid size and mean shape score. B, Log centroid size and PC1 scores. C, Log centroid size and PC2 scores. D, Log centroid size and PC3 scores. E, Log centroid size and PC4 scores. F, Log centroid size and PC5 scores. Each oval indicates confidence ellipse for each order to show the spread of its plots. 


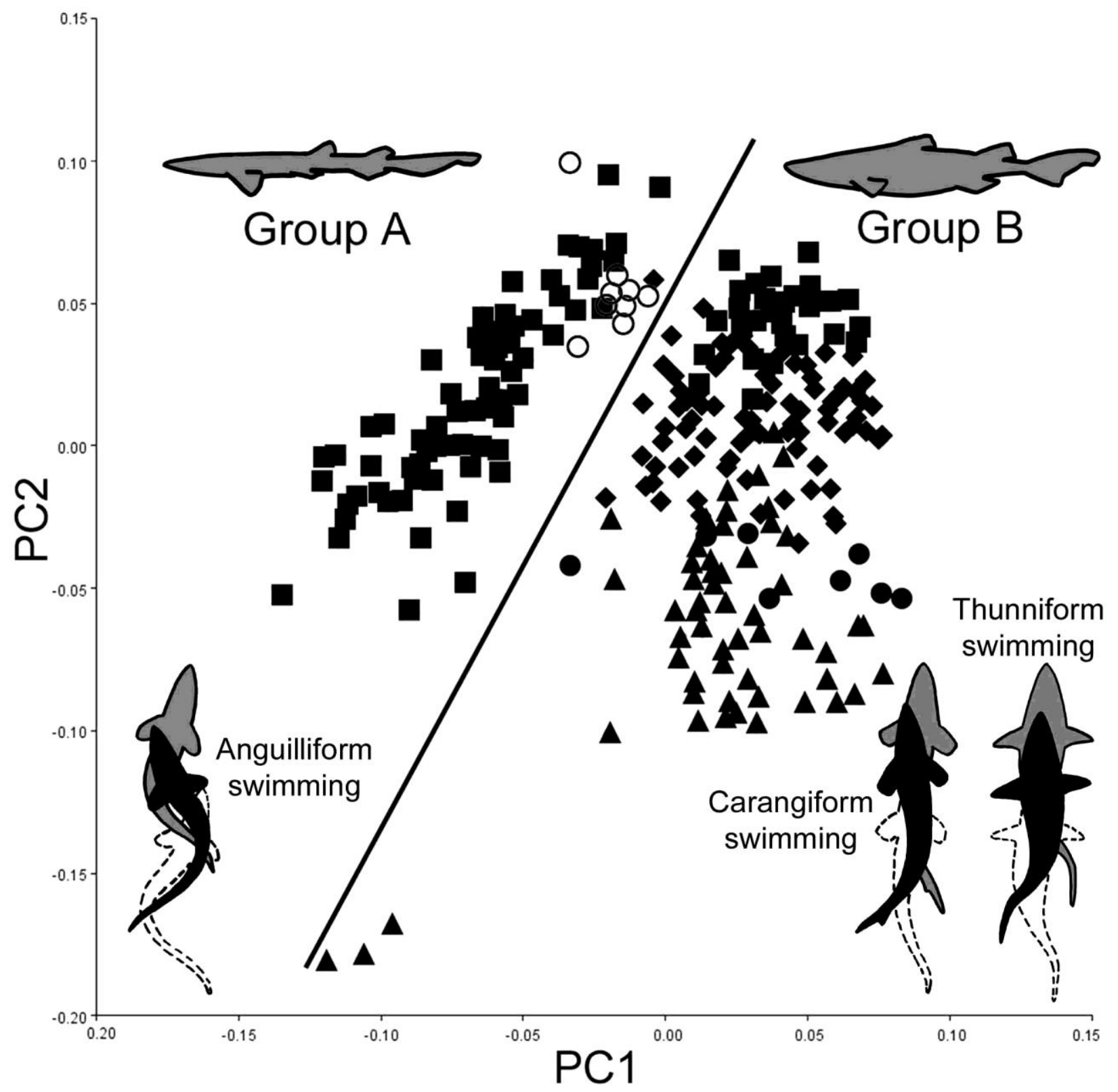

Figure 6. Scatter plot diagram showing division (line) between Group A and Group B of full body analysis (cf. Fig. 4B) where plots consist only of pristiophoriform and squatiniform taxa (open circles) and species of genera examined by Thomson \& Simanek (1977) (solid circles, Group 1 sharks; triangles, Group 2 sharks; squares, Group 3 sharks; diamonds, Group 4 sharks). Top two silhouette images of sharks in lateral view represent respective generalized body form of taxa located at approximate center of each of the two main clusters of plots in Figure 4B (example of species used for each silhouette: Groups A, Bythaelurus hispidius; Group $\mathrm{B}$, Centroscyllium kamoharai). Bottom three silhouette images of sharks in dorsal view illustrate three swimming modes and their distribution by body form group (see text; modified after CC Lindsey's illustration reproduced by Sfakiotakis et al., 1999, fig. 7). 

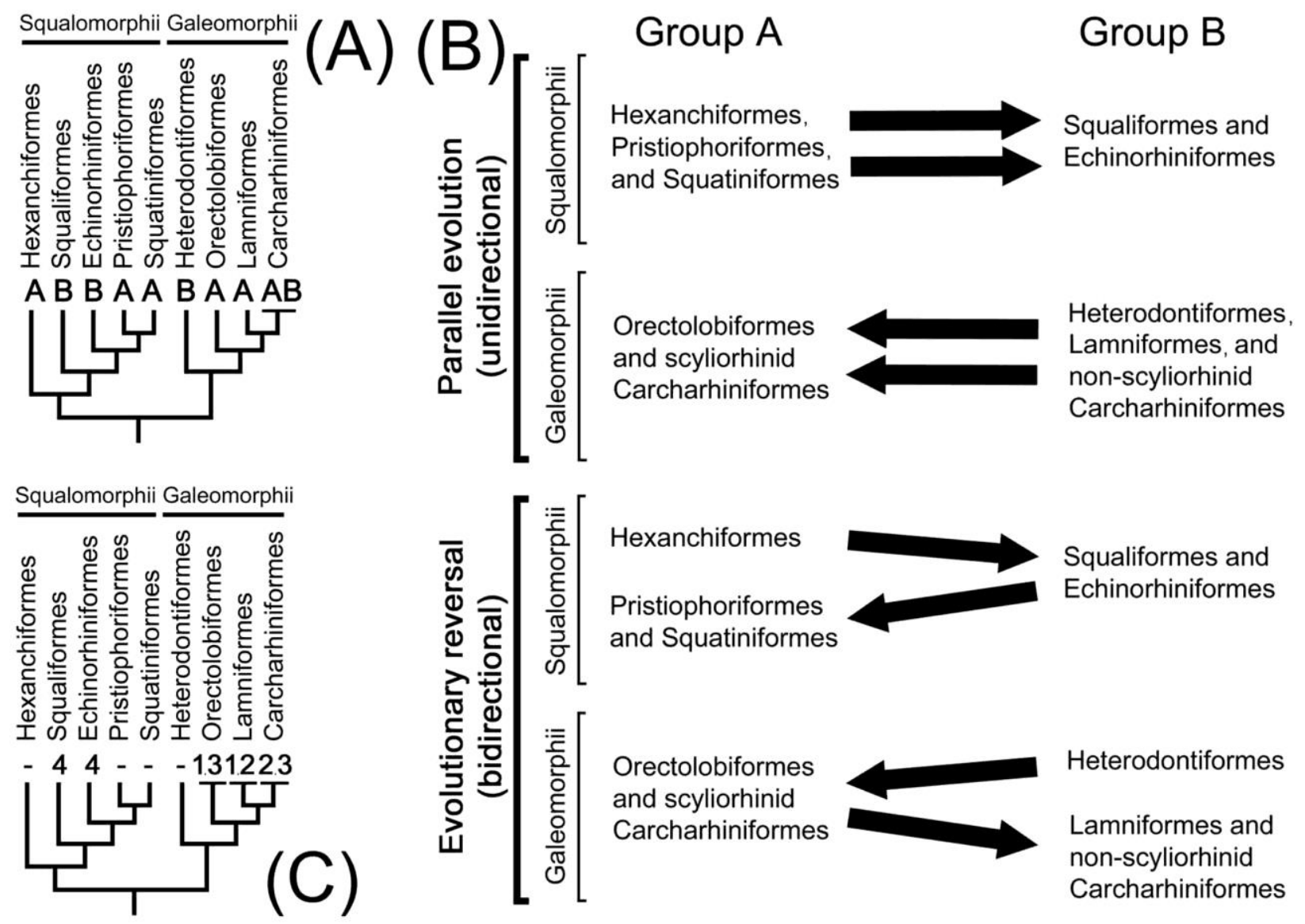

Figure 7. Possible evolutionary scenarios of body forms in sharks. A, Distribution of Group A and Group B body forms by shark orders mapped onto Naylor et al.'s (2012; see also Fig. 1A) phylogenetic tree. B, Two alternative conceptual evolutionary pathways between Group A and Group B body forms (Figs. 4B, 6) in each of the two superorders, Squalomorphii and Galeomorphii. C, Distribution of Thomson \& Simanek's (1977) Groups 1, 2, 3, and 4 body forms (Figs. 1B, 6) by shark orders mapped onto Naylor et al.'s (2012; see also Fig. 1A) phylogenetic tree (dashes indicate taxa that were not included in Thomson \& Simanek's study). 
Appendix 1. List of all extant species of sharks examined in this study showing the species code, common name, maximum total length ( $\operatorname{maxTL}$; in $\mathrm{cm}$ ), and page number where each illustration used for geometric morphometric analyses is located in Ebert et al.'s (2013) book. Asterisk (*) indicates genus in which all of its members (20 species) are examined as one taxon because only one representative lateral view was presented for the entire genus in Ebert et al.'s (2013) book.

\begin{tabular}{|c|c|c|c|c|}
\hline Code & Scientific name & Common name & $\operatorname{maxTL}$ & Page \\
\hline \multicolumn{5}{|c|}{ HEXANCHIFORMES } \\
\hline \multicolumn{5}{|c|}{ Chlamydoselachidae } \\
\hline 1 & Chlamydoselachus africana & South African frilled shark & 117 & 66 \\
\hline 2 & Chlamydoselachus anguineus & Frilled shark & 196 & 67 \\
\hline \multicolumn{5}{|c|}{ Hexanchidae } \\
\hline 3 & Heptranchias perlo & Sharpnose sevengill shark & 139 & 68 \\
\hline 4 & Hexanchus nakamurai & Bigeye sixgill shark & 180 & 68 \\
\hline 5 & Hexanchus griseus & Bluntnose sixgill shark & 550 & 69 \\
\hline 6 & Notorynhchus cepedianus & Broadnose sevengill shark & 296 & 70 \\
\hline \multicolumn{5}{|c|}{ ECHINORHINIFORMES } \\
\hline \multicolumn{5}{|c|}{ Echinorhinidae } \\
\hline 7 & Echinorhinus brucus & Bramble shark & 310 & 72 \\
\hline 8 & Echinorhinus cookei & Prickly shark & 450 & 72 \\
\hline \multicolumn{5}{|c|}{ SQUALIFORMES } \\
\hline \multicolumn{5}{|c|}{ Squalidae } \\
\hline 9 & Cirrhagaleus asper & Roughskin spurdog & 118 & 81 \\
\hline 10 & Cirrhagaleus australis & Southern Mandarin dogfish & 123 & 81 \\
\hline 11 & Cirrhgaleus barbifer & Mandarin dogfish & 122 & 82 \\
\hline 12 & Squalus acanthias & Piked dogfish & 200 & 83 \\
\hline 13 & Squalus albifrons & Eastern highfin spurdog & 86 & 84 \\
\hline 14 & Squalus altipinnis & Western highfin spurdog & 59 & 84 \\
\hline 15 & Squalus blainville & Longnose spurdog & 89 & 85 \\
\hline 16 & Squalus brevirostris & Japanese shortnose spurdog & 59 & 85 \\
\hline 17 & Squalus bucephalus & Bighead spurdog & 90 & 86 \\
\hline 18 & Squalus chloroculus & Greeneye spurdog & 99 & 86 \\
\hline 19 & Squalus crassispinus & Fastspine spurdog & 58 & 87 \\
\hline 20 & Squalus cubensis & Cuban dogfish & 110 & 87 \\
\hline 21 & Squalus edmundsi & Edmund's spurdog & 87 & 88 \\
\hline 22 & Squalus formosus & Taiwan spurdog & 81 & 88 \\
\hline 23 & Squalus graham & Eastern longnose spurdog & 73 & 89 \\
\hline 24 & Squalus griffin & New Zealand dogfish & 110 & 89 \\
\hline 25 & Squalus hemipinnis & Indonesian shortsnout dogfish & 74 & 90 \\
\hline 26 & Squalus japonicus & Japanese spurdog & 95 & 90 \\
\hline 27 & Squalus lalannei & Seychelles spurdog & 79 & 91 \\
\hline 28 & Squalus megalops & Shortnose spurdog & 77 & 91 \\
\hline 29 & Squalus melanurus & Blacktail spurdog & 75 & 92 \\
\hline 30 & Squalus mitsukurii & Shortspine spurdog & 125 & 92 \\
\hline
\end{tabular}


$31 \quad$ Squalus montalbani

32 Squalus nasutus

33 Squalus notocaudatus

34 Squalus rancureli

35 Squalus raolensis

36 Squalus suckleyi

Centrophoridae

37 Centrophorus acus

38 Centrophorus altromarginatus

39 Centrophorus granulosus

$40 \quad$ Centrophorus harrisoni

41 Centrophorus isodon

42 Centrophorus lusitanicus

43 Centrophorus mouccenisis

44 Centrophorus niakung

45 Centrophorus seychellorum

46 Centrophorus squamosus

$47 \quad$ Centrophorus tessellatus

48 Centrophorus westraliensis

49 Centrophorus zeehaani

50 Deania calcea

51 Deania hystricosa

52 Deania profundorum

53 Deania quadrispinosa

Etompteridae

54 Aculeola nigra

55 Centroscyllium excelsum

56 Centroscyllium fabricii

57 Centroscyllium granulatum

58 Centroscyllium kamoharai

59 Centroscyllium nigrum

60 Centroscyllium ornatum

61 Centroscyllium ritteri

62 Etmopterus baxteri

63 Etmopterus bigelowi

64 Etmopterus brachyurus

65 Etmopterus bullisi

66 Etmopterus burgessi

$67 \quad$ Etmopterus carteri

68 Etmopterus caudistigmus

69 Etmopterus compagnoi

70 Etmopterus decacuspidatus

71 Etmopterus dianthus

72 Etmopterus dislineatus

73 Etmopterus evansi

74 Etmopterus fusus $\begin{array}{lll}\text { Philippines spurdog } & 101 & 93\end{array}$

Western longnose spurdog $\quad 77 \quad 93$

$\begin{array}{lll}\text { Bartail spurdog } & 62 & 94\end{array}$

$\begin{array}{lll}\text { Cyrano spurdog } & 77 & 94\end{array}$

Kermadec spiny dogfish $\quad 73 \quad 95$

North Pacific spiny dogfish $\quad 150 \quad 95$

$\begin{array}{lll}\text { Needle dogfish } & 161 & 101\end{array}$

Dwarf gulper shark $\quad 94 \quad 101$

Gulper shark $\quad 110 \quad 102$

Longnose gulper shark $\quad 114 \quad 102$

Blackfin gulper shark $\quad 108 \quad 103$

Lowfin gulper shark $\quad 100 \quad 103$

Smallfin gulper shark $\quad 100 \quad 104$

Taiwan gulper shark $\quad 170 \quad 104$

Seychelles gulper shark $\quad 80 \quad 105$

Leafscale gulper shark $\quad 164 \quad 105$

Mosaic gulper shark $\quad 89 \quad 106$

Western gulper shark $\quad 91 \quad 106$

Southern dogfish $\quad 108 \quad 107$

Birdbeak dogfish $\quad 122 \quad 108$

Rough longnose dogfish $\quad 111 \quad 108$

$\begin{array}{lll}\text { Arrowhead dogfish } & 97 & 109\end{array}$

$\begin{array}{lll}\text { Longsnout dogfish } & 114 & 109\end{array}$

Hooktooth dogfish $\quad 121 \quad 121$

Highfin dogfish $\quad 64 \quad 121$

Black dogfish $\quad 107 \quad 122$

Granular dogfish $\quad 28 \quad 122$

Bareskin dogfish $\quad 63 \quad 123$

Combtooth dogfish $\quad 52 \quad 123$

$\begin{array}{lll}\text { Ornate dogfish } & 30 & 124\end{array}$

Whitefin dogfish $\quad 43 \quad 124$

Giant lanternshark $\quad 86 \quad 125$

Blurred smooth lanternshark $\quad 72 \quad 125$

Shorttail lanternshark $\quad 42 \quad 126$

Lined lanternshark $\quad 27 \quad 126$

Broadsnout lanternshark $\quad 41 \quad 127$

Cylindrical lanternshark $\quad 21 \quad 127$

Tailspot lanternshark $\quad 34 \quad 128$

Brown lanternshark $\quad 67 \quad 128$

Combtooth lanternshark $\quad 29 \quad 129$

Pink lanternshark $\quad 41 \quad 129$

Lined lanternshark $\quad 45 \quad 130$

Blackmouth lanternshark $\quad 32 \quad 130$

$\begin{array}{lll}\text { Pygmy lanternshark } & 30 & 131\end{array}$ 


$\begin{array}{ll}75 & \text { Etmopterus gracilispnis } \\ 75 & \text { Etmopterus granulosus } \\ 76 & \text { Etmopterus hillianus } \\ 77 & \text { Etmopterus joungi } \\ 78 & \text { Etmopterus litvinovi } \\ 79 & \text { Etmopterus lucifer } \\ 80 & \text { Etmopterus molleri } \\ 81 & \text { Etmopterus perryi } \\ 82 & \text { Etmopterus polli } \\ 83 & \text { Etmopterus princeps } \\ 84 & \text { Etmopterus pseudosqualiolus } \\ 85 & \text { Etmopterus pusillus } \\ 86 & \text { Etmopterus pycnolepis } \\ 87 & \text { Etmopterus robinsi } \\ 88 & \text { Etmopterus schultzi } \\ 89 & \text { Etmopterus sculptus } \\ 90 & \text { Etmopterus sentosus } \\ 91 & \text { Etmopterus sheikoi } \\ 92 & \text { Etmopterus spinax } \\ 93 & \text { Etmopterus splendidus } \\ 94 & \text { Etmopterus unicolor } \\ 95 & \text { Etmopterus viator } \\ 96 & \text { Etmopterus villosus } \\ 97 & \text { Etmopterus virens } \\ 98 & \text { Trigonognathus kabeyai } \\ \text { Somniosidae } & \text { Centroscymnus coelolepis } \\ 99 & \text { Oxynotus bruniensis } \\ 100 & \text { Centroscymns owstoni } \\ 101 & \text { Centroselachus crepidater } \\ 102 & \text { Proscymnodon macracanthus } \\ 103 & \text { Proscymnodon plunketi } \\ 104 & \text { Scymnodalatias albicauda } \\ 105 & \text { Scymnodalatias garricki } \\ 106 & \text { Scymnodalatias oligodon } \\ 107 & \text { Scymnodalatias sherwoodi } \\ 108 & \text { Scymnodon ringens } \\ 109 & \text { Somniosus antarcticus } \\ 110 & \text { Somniosus longus } \\ 111 & \text { Somniosus microcephalus } \\ 112 & \text { Somniosus pacificus } \\ 113 & \text { Somniosus rostratus } \\ 114 & \text { Zameus ichiharai } \\ \text { Oxynotidae } \text { squamulosus } \\ \end{array}$

Broadband lanternshark $\quad 33$

131

Southern lanternshark $\quad 85 \quad 132$

Caribbean lanternshark $\quad 28 \quad 132$

Shortfin smooth lanternshark $\quad 46 \quad 133$

Smalleye lanternshark $\quad 61 \quad 133$

Blackbelly lanternshark $\quad 47 \quad 134$

Slendertail lanternshark $\quad 46 \quad 134$

Dwarf lanternshark $\quad 21 \quad 135$

African lanternshark $\quad 24 \quad 135$

Great lanternshark $\quad 89 \quad 136$

False lanternshark $\quad 45 \quad 136$

Smooth lanternshark $\quad 50 \quad 137$

Denescale lanternshark $\quad 45 \quad 137$

West Indian lanternshark $\quad 34 \quad 138$

Fringefin lanternshark $\quad 30 \quad 138$

Sculptured lanternshark $\quad 53 \quad 139$

Thorny lanternshark $\quad 27 \quad 139$

Rasptooth dogfish $\quad 43 \quad 140$

Velvet belly $\quad 41 \quad 140$

Splendid lanternshark $\quad 26 \quad 141$

Brown lanternshark $\quad 79 \quad 141$

Traveller lanternshark $\quad 58 \quad 142$

Hawaiian lanternshark $\quad 17 \quad 142$

Green lanternshark $\quad 26 \quad 143$

Viper dogfish $\quad 54 \quad 143$

Portuguese dogfish $\quad 122 \quad 151$

Roughskin dogfish $\quad 120 \quad 151$

Longnose velvet dogfish $\quad 105 \quad 152$

Largespine velvet dogfish $\quad 68 \quad 152$

Plunket's shark $\quad 170 \quad 153$

Whitetail dogfish $\quad 110 \quad 153$

Azores dogfish $\quad 40 \quad 154$

Sparsetooth dogfish $\quad 26 \quad 154$

Sherwood dogfish $\quad 85 \quad 155$

Knifetooth dogfish $\quad 110 \quad 155$

Southern sleeper Shark $\quad 600 \quad 156$

Frog shark $\quad 140 \quad 156$

Greenland shark $\quad 730 \quad 157$

Pacific sleeper shark $\quad 700 \quad 158$

Little sleeper shark $\quad 143 \quad 158$

Japanese velvet dogfish $\quad 146 \quad 159$

$\begin{array}{lll}\text { Velvet dogfish } & 84 & 159\end{array}$

Prickly dogfish $\quad 91 \quad 162$

Caribbean roughshark $\quad 49 \quad 163$ 
118 Oxynotus centrina

119 Oxynotus japonicus

120 Oxynotus paradoxus

Dalatiidae

121 Dalatias licha

122 Euprotomicroides zantedeschia

123 Euprotomicrus bispinatus

124 Heteroscymnoides marleyi

125 Isistius brasiliensis

126 Isistius labialis

127 Isistius plutodus

128 Mollisquama parini

129 Squaliolus aliae

130 Squaliolus laticaudus

PRISTIOPHORIFORMES

Pristiophoridae

131 Pilotrema warreni

132 Pristiophorus cirratus

133 Pristiophorus delicatus

134 Pristiophorus japonicus

135 Pristiophorus nancyae

136 Pristiophorus nudipinnis

137 Pristiophorus schroederi

138 Pristiophorus sp. C

SQUATINIFORMES

Squatinidae

139 Squatina spp.*

HETERODONTIFORMES

Heterodontidae

140 Heterodontus francisci

141 Heterodontus galeatus

142 Heterodontus japonicus

143 Heterodontus mexicanus

144 Heterodontus omanensis

145 Heterodontus portusjacksoni

146 Heterodontus quoyi

147 Heterodontus ramalheira

148 Heterodontus zebra

LAMNIFORMES

Mitsukurinidae

149 Mitsukurina owstoni

Odontaspididae

150 Carcharias taurus

151 Odontaspis ferox

152 Odontaspis noronhai

Pseudocarchariidae
Angular roughshark

Japanese roughshark

54

Sailfin roughshark

118

164

Kitefin shark 182

168

Taillight shark

41

Pygmy shark

27

Longnose pygmy shark $\quad 37$

Cookiecutter shark $\quad 50$

South China cookiecutter shark 44

Largetooth cookiecutter shark

42

Pocket shark

40

Smalleye pygmy shark

22

28

136

149

179

Sixgill sawshark

179

Longnose sawshark

\section{5}

Japanese sawshark

153

African dwarf sawshark

62

Shortnose sawshark

124

Bahamas sawshark

81

73

180

180

181

Philippine sawshark

181

182

182

'Angel sharks'

244

183

Horn shark

122

203

Crested bullhead shark

130

208

Japanese bullhead shark

120

208

Mexican hornshark

70

209

Oman bullhead shark

209

Port Jackson shark

61

210

Galapagos bullhead shark

237

211

Whitespotted bullhead shark

212

Zebra bullhead shark

83

122

212

Goblin shark

550

216

Sandtiger shark

430

217

Smalltooth sandtiger

450

218

Bigeye sandtiger

427 
153 Pseudocarcharias kamoharai

Megachasmidae

154 Megachasma pelagios

Cetorhinidae

155 Cetorhinus maximus

Alopiidae

156 Alopias vulpinus

157 Alopias pelagicus

158 Alopias superciliosus

Lamnidae

159 Carcharodon carcharias

160 Isurus oxyrinchus

161 Isurus paucus

162 Lamna ditropis

163 Isurus nasus

ORECTOLOBIFORMES

Parascylliidae

164 Cirrhoscyllium expolitum

165 Cirrhoscyllium formosanum

166 Cirrhoscyllium japonicum

167 Parascyllium collare

168 Parascyllium elongatum

169 Parascyllium ferrugineum

170 Parascyllium sparsimaculatum

171 Parascyllium variolatum

Brachaeularidae

172 Brachaelurus colcloughi

173 Brachaelurus waddi

Orectolobidae

174 Eucrossorhinus dasypogon

175 Orectolobus floridus

176 Orectolobus halei

177 Orectolobus hutchinsi

178 Orectolobus japonicus

179 Orectolobus leptolineatus

180 Orectolobus maculatus

181 Orectolobus ornatus

182 Orectolobus parvimaculatus

183 Orectolobus reticalatus

184 Orectolobus wardi

185 Sutorectus tenataculatus

Hemiscylliidae

186 Chiloscyllium arabicum

187 Chiloscyllium burmensis

188 Chiloscyllium griseum

189 Chiloscyllium hasselti
Crocodile shark

122

219

Megamouth shark

$>550$

219

Basking shark

$>1,000$

222

Thresher shark

635

223

Pelagic thresher

365

480

226

Bigeye thresher

226

White shark

600

400

430

305

355

227

Shortfin mako

230

Longfin mako

231

Salmon shark

Porbeagle shark

231

232

Barbelthroat carpetshark $\quad 33.5 \quad 236$

Taiwan saddled carpetshark $\quad 39 \quad 236$

Saddled carpetshark

49

Collared carpetshark

237

Elongate carpet shark

Rusty carpetshark

87

237

42

238

Sparsely spotted carpetshark

238

Necklace carpetshark

80

239

239

Bluegrey carpetshark

240

Blind shark

75

120

241

Tasselled wobbegong

125

248

Florida banded wobbegong

75

248

Gulf wobbegong

206

149

249

Western wobbegong

Japanese wobbegong

118

249

False cobbler wobbegong

120

250

Spotted wobbegong

250

Ornate wobbegong

170

251

$110 \quad 251$

Dwarf spotted wobbegong

94

252

Network wobbegong

Northern wobbegong

52

252

Cobbler wobbegong

100

253

92

253

Arabian carpetshark

70

258

Burmese bambooshark

259

Grey bambooshark

57

259

Indonesian bambooshark 
190 Chiloscyllium indicum

191 Chiloscyllium plagiosum

192 Chiloscyllium punctatum

193 Hemiscyllium freycineti

194 Hemiscyllium galei

195 Hemiscyllium hallstromi

196 Hemiscyllium henryi

197 Hemiscyllium michaeli

198 Hemiscyllium ocellatum

199 Hemiscyllium strahani

200 Hemiscyllium trispeculare

Stegostomatidae

201 Stegostoma fasciatum

Ginglymostomatidae

202 Pseudoginglymostoma brevicaudatum Shorttail nurse shark

203 Ginglymostoma cirratum

204 Nebrius ferrungineus

Rhincodontidae

205 Rhincodon typus

CARCHARHINIFORMES

Scyliorhinidae

206 Apristurus albisoma

207 Apristurus ampliceps

208 Apristurus aphyodes

209 Apristurus australis

210 Apristurus brunneus

211 Apristurus bucephalus

212 Apristurus canutus

213 Apristurus exsanguis

214 Apristurus fedorovi

215 Apristurus gibbosus

216 Apristurus herklotsi

217 Apristurus indicus

218 Apristurus internatus

219 Apristurus investigatoris

220 Apristurus japonicus

221 Apristurus kampae

222 Apristurus laurussonii

223 Apristurus longicephalus

224 Apristurus macrorhynchus

225 Apristurus macrostomus

226 Apristurus manis

227 Apristurus melanoasper

228 Apristurus microps

229 Apristurus micropterygeus

230 Apristurus nasutus
Slender bambooshark $\quad 65 \quad 260$

Whitespotted bambooshark $\quad 95 \quad 261$

Brownbanded bambooshark $\quad 132 \quad 261$

Indonesian speckled carpetshark $72 \quad 262$

Gale's epaulette shark $\quad 57 \quad 262$

Paupian epaulette carpetshark $\quad 77 \quad 263$

Henry's epaulette shark $\quad 70 \quad 263$

Michael's epaulette shark $\quad 82 \quad 264$

Epaulette carpetshark $\quad 107 \quad 264$

Hooded carpetshark $\quad 80 \quad 265$

Speckled carpetshark $\quad 79 \quad 265$

$\begin{array}{lll}\text { Zebra shark } & 235 & 268\end{array}$

Tawny nurse shark $\quad 320 \quad 271$

$\begin{array}{lll}\text { Whale shark } & 2,100 \quad 272\end{array}$

White-bodied catshark $\quad 60 \quad 284$

$\begin{array}{lll}\text { Roughskin catshark } & 87 & 284\end{array}$

White ghost catshark $\quad 54 \quad 285$

Pinocchio catshark $\quad 62 \quad 285$

Brown catshark $\quad 69 \quad 286$

Bighead catshark $\quad 68 \quad 286$

Hoary catshark $\quad 46 \quad 287$

Flaccid catshark $\quad 91 \quad 287$

$\begin{array}{lll}\text { Stout catshark } & 68 & 288\end{array}$

Humpback catshark $\quad 51 \quad 288$

$\begin{array}{lll}\text { Longfin catshark } & 49 & 289\end{array}$

Smallbelly catshark $\quad 34 \quad 289$

Shortnose demon catshark $\quad 42 \quad 290$

Broadnose catshark $\quad 26 \quad 291$

Japanese catshark $\quad 71 \quad 291$

Longnose catshark $\quad 65 \quad 291$

Iceland catshark $\quad 72 \quad 292$

Longhead catshark $\quad 59 \quad 292$

Flathead catshark $\quad 66 \quad 293$

Broadmouth catshark $\quad 38 \quad 293$

Ghost catshark $\quad 88 \quad 294$

Fleshynose catshark $\quad 79 \quad 294$

Smalleye catshark $\quad 61 \quad 295$

Smalldorsal catshark $\quad 37 \quad 295$

Largenose catshark $\quad 59 \quad 296$ 
231 Apristurus parvipinnis

232 Apristurus pinguis

233 Apristurus platyrhynchus

234 Apristurus profundorum

235 Apristurus riveri

236 Apristurus saldanha

237 Apristurus sibogae

238 Apristurus sinensis

239 Apristurus spongiceps

240 Apristurus stenseni

241 Asymbolus analis

242 Asymbolus funebris

243 Asymbolus galacticus

244 Asymbolus occiduus

245 Asymbolus pallidus

246 Asymbolus parvus

247 Asymbolus rubiginosus

248 Asymbolus submaculatus

249 Asymbolus vincenti

250 Atelomycterus basiliensis

251 Atelomycterus fasciatus

252 Atelomycterus macleaya

253 Atelomycterus marmoratus

254 Atelomycterus marnkalha

255 Aulohalaelurus kanakorum

256 Aulohalaelurus labiosus

257 Bythaelurus canescens

258 Bythaelurus clevai

259 Bythaelurus dawsoni

260 Bythaelurus giddingsi

261 Bythaelurus hispidus

262 Bythaelurus immaculatus

263 Bythaelurus incanus

264 Bythaelurus lutarius

265 Cephaloscyllium albipinnum

266 Cephaloscyllium cooki

267 Cephaloscyllium fasciatum

268 Cephaloscyllium hiscosellum

269 Cephaloscyllium isabellum

270 Cephaloscyllium laticeps

271 Cephaloscyllium maculatum

272 Cephaloscyllium pardelotum

273 Cephaloscyllium pictum

274 Cephaloscyllium sarawakensis

275 Cephaloscyllium signourum

276 Cephaloscyllium silasi
Smallfin catshark $\quad 52$

Bulldog catshark 65

Spatulasnout catshark $\quad 71$

Deepwater catshark $\quad 76$

Broadgill catshark

Saldanha catshark

48

89

Pale catshark

\section{1}

South China catshark

Spongehead catshark

Panama ghost catshark

Grey harspotted catshark

Blotched catshark

Starry catshark

Western spotted catshark

Pale spotted catshark

Dwarf catshark

Orange spotted catshark

Variegated catshark

Gulf catshark

Bali catshark

Banded sand catshark

Australian marbled catshark

Coral catshark

Whitespotted sand catshark

New Caledonia catshark

Blackspotted catshark

Dusky catshark

Broadhead catshark

New Zealand catshark

Jaguar catshark

Bristly catshark

Spotless catshark

Dusky catshark

Mud catshark

Whitefin swellshark

Cook's swellshark

Reticulated swellshark

Australian reticulated swellshark 52

Draughtsboard shark

Australian swellshark

Leopard-spottd swellshark $\quad 20$

Painted swellshark $\quad 72$

Sarawak swellshark

Flagtail swellshark

Indian swellshark
296

297

297

298

298

299

299

300

300

301

301

306

306

307

307

308

308

309

309

310

310

311

311

312

313

313

316

316

317

317

318

318

319

319

324

324

325

325

326

326

327

327

328

328

329

329 
277 Cephaloscyllium speccum

278 Cephaloscyllium stevensi

279 Cephaloscyllium sufflans

280 Cephaloscyllium umbratile

281 Cephaloscyllium variegatum

282 Cephaloscyllium ventriosum

283 Cephaloscyllium zebrum

284 Cephalurus cephalus

285 Figaro boardmani

286 Figaro striatus

287 Galeus antillensis

288 Galeus area

289 Galeus atlanticus

290 Galeus cadenati

291 Galeus eastmani

292 Galeus gracilis

293 Galeus longirostris

294 Galeus melastomus

295 Galeus mincaronei

296 Galeus murinus

297 Galeus nipponensis

298 Galeus piperatus

299 Galeus polli

300 Galeus priapus

301 Galeus sauteri

302 Galeus schultzi

303 Galeus springeri

304 Halaelurus boesmani

305 Halaelurus buergeri

306 Halaelurus lineatus

307 Halaelurus maculosus

308 Halaelurus natalensis

309 Halaelurus quagga

310 Halaelurus sellus

311 Haploblepharus edwardsii

312 Haploblepharus fuscus

313 Haploblepharus kistnasamyi

314 Haploblepharus pictus

315 Holohalaelurus favus

316 Holohalaelurus grennian

317 Holohalaelurus melanostigma

318 Holohalaelurus punctatus

319 Holohalaelurus regani

320 Parmaturus albimarginatus

321 Parmaturus albipenis

322 Parmaturus bigus
Speckled swellshark

69

Steven's swellshark 66

Balloon shark 110

Japanese swellshark

Swellshark

100

Narrowbar swellshark

45

Lollipop catshark

30

Australian sawtail catshark

Northern sawtail catshark

Antilles catshark

Roughtail catshark

Atlantic sawtail catshark

Longfin sawtail catshark

Gecko catshark

Slender sawtail catshark

Longnose sawtail catshark

Blackmouth catshark

Southern sawtail catshark

Mouse catshark

Broadfin sawtail catshark

Peppered catshark

African sawtail catshark

Phallic catshark

Blacktip sawtail catshark

Dwarf sawtail shark

Springer's sawtail shark

Speckled catshark

Blackspotted catshark

Lined catshark

Indonesian speckled catshark

Tiger catshark

Quagga catshark

Rusty catshark

Puffader shyshark

Brown shyshark

Natal shyshark

Dark shyshark

Honeycomb izak catshark

Grinning izak

Crying izak catshark

African spotted catshark

Izak catshark

Whitetip catshark

White-clasper catshark

Beige catshark
330

330

331

331

332

332

333

333

338

338

339

339

340

340

341

341

342

342

343

343

344

344

345

345

346

346

347

350

350

351

351

352

352

353

354

354

355

355

358

358

359

359

360

361

361

364 
323 Parmaturus compechiensis

324 Parmaturus lanatus

325 Parmaturus macmillani

326 Parmaturus melanobranchius

327 Parmaturus pilosus

328 Parmaturus xaniurus

329 Pentanchus profundicolus

330 Poroderma africanum

331 Poroderma pantherium

332 Schroederichthys bivius

333 Schroederichthys chilensis

334 Schroederichthys maculatus

335 Schroederichthys saurisquaus

336 Schroederichthys tenuis

337 Scyliorhinus besnardi

338 Scyliorhinus boa

339 Scyliorhinus canicular

340 Scyliorhinus capensis

341 Scyliorhinus cervigoni

342 Scyliorhinus comoroensis

343 Scyliorhinus garmani

344 Scyliorhinus haeckelii

345 Scyliorhinus hesperius

346 Scyliorhinus meadi

347 Scyliorhinus rotifer

348 Scyliorhinus stellaris

349 Scyliorhinus tokubee

350 Scyliorhinus torazame

351 Scyliorhinus torrei

Proscylliidae

352 Ctenacis fehlmanni

353 Eridacnis barbouri

354 Eridacnis radcliffei

355 Eridacnis sinuans

356 Proscyllium habereri

357 Proscyllium magnificum

Pseudotriakidae

358 Gollum attenuates

359 Gollum suluensis

360 Gollum sp. B

361 Pseudotriakis microdon

362 Planonasus parini

Leptochariidae

363 Leptocharias smithii

Triakidae

364 Furgaleus macki
Campeche catshark $\quad 16$

Velvet catshark 364

New Zealand filetail $\quad 53 \quad 365$

Blackgill catshark $\quad 85 \quad 366$

Salamander catshark $\quad 64 \quad 366$

Filetail catshark $\quad 61 \quad 367$

Onefin catshark $\quad 51 \quad 367$

$\begin{array}{lll}\text { Pyjama shark } & 97 & 370\end{array}$

$\begin{array}{lll}\text { Leopard catshark } & 77 & 370\end{array}$

$\begin{array}{lll}\text { Narrowmouth catshark } & 82 & 371\end{array}$

Redspotted catshark $\quad 70 \quad 371$

Narrowtail catshark $\quad 35 \quad 376$

Lizard catshark $\quad 70 \quad 376$

$\begin{array}{lll}\text { Slender catshark } & 47 & 377\end{array}$

$\begin{array}{lll}\text { Polkadot catshark } & 47 & 377\end{array}$

Boa catshark $\quad 54 \quad 378$

Smallspotted catshark $\quad 100 \quad 378$

$\begin{array}{lll}\text { Yellowspotted catshark } & 122 & 379\end{array}$

West African catshark $\quad 76 \quad 379$

Comoro catshark $\quad 46 \quad 380$

Brownspotted catshark $\quad 36 \quad 380$

Freckled catshark $\quad 50 \quad 381$

Whitesaddled catshark $\quad 47 \quad 381$

Blotched catshark $\quad 49 \quad 382$

Chain catshark $\quad 59 \quad 382$

Nursehound $\quad 162 \quad 383$

Izu catshark $\quad 41 \quad 383$

$\begin{array}{lll}\text { Cloudy catshark } & 48 & 384\end{array}$

Dwarf catshark $\quad 32 \quad 384$

Harlequin catshark $\quad 46 \quad 385$

Cuban ribbontail catshark $\quad 34 \quad 388$

$\begin{array}{lll}\text { Pygmy ribbontail catshark } & 24 & 388\end{array}$

African ribbontail catshark $\quad 37 \quad 389$

Graceful catshark $\quad 65 \quad 389$

Magnificent catshark $\quad 49 \quad 390$

Slender smoothhound $\quad 110 \quad 391$

Sulu gollumshark $\quad 65 \quad 391$

Whitemarked gollumshark $\quad 60 \quad 392$

False catshark $\quad 295 \quad 392$

Pygmy false catshark $\quad 56 \quad 393$

Barbeled houndshark $\quad 82 \quad 393$

$\begin{array}{lll}\text { Whiskery shark } & 160 & 407\end{array}$ 
365 Gogolia filewoodi

366 Galeorhinus galeus

367 Hemitriakis abdita

368 Hemitriakis complicofasciata

369 Hemitriakis falcata

370 Hemitriakis indroyonoi

371 Hemitriakis japonica

373 Hemitriakis leucoperiptera

374 Hypogaleus hyugaensis

375 Iago garricki

376 Iago mangalorensis

377 Iago omanensis

378 Mustelus albipinnis

379 Mustelus antarcticus

380 Mustelus asterias

381 Mustelus californicus

382 Mustelus canis

383 Mustelus dorsalis

384 Mustelus fasciatus

385 Mustelus griseus

386 Mustelus henlei

387 Mustelus higmani

388 Mustelus lenticulatus

389 Mustelus lunulatus

390 Mustelus manazo

391 Mustelus mento

392 Mustelus minicanis

393 Mustelus mosis

394 Mustelus mustelus

395 Mustelus norrisi

396 Mustelus palumbes

397 Mustelus punctulatus

398 Mustelus ravidus

399 Mustelus schmitti

400 Mustelus sinusmexicanus

401 Mustelus stevensi

402 Mustelus walker

403 Mustelus whitneyi

404 Mustelus widodoi

405 Scylliogaleus quecketti

406 Triakis acutipinna

407 Triakis maculata

408 Triakis megalopterus

409 Triakis scyllium

410 Triakis semifasciata

Hemigaleidae
Sailback houndshark $\quad 74 \quad 407$

Tope $\quad 195 \quad 408$

Deepwater sicklefin houndshark $80 \quad 409$

Striped topeshark $\quad 93 \quad 409$

Sicklefin houndshark $\quad 77 \quad 410$

Indonesian houndshark $\quad 120 \quad 410$

Japanese topeshark $\quad 120 \quad 411$

Whitefin topeshark $\quad 96 \quad 411$

Blacktip topeshark $\quad 130 \quad 412$

$\begin{array}{lll}\text { Longnose houndshark } & 75 & 412\end{array}$

Mangalore houndshark $\quad 41 \quad 413$

Bigeye houndshark $\quad 58 \quad 413$

White-margin fin houndshark $\quad 118 \quad 414$

$\begin{array}{lll}\text { Gummy shark } & 185 & 414\end{array}$

Starry smoothhound $\quad 140 \quad 415$

Grey smoothhound $\quad 125 \quad 415$

Dusky smoothhound $\quad 150 \quad 416$

Sharptooth smoothhound $\quad 64 \quad 416$

Striped smoothhound $\quad 155 \quad 417$

Spotless smoothhound $\quad 101 \quad 417$

Brown smoothound $\quad 100 \quad 418$

Smalleye smoothhound $\quad 64 \quad 418$

$\begin{array}{lll}\text { Rig } & 151 & 419\end{array}$

Sicklefin smoothhound $\quad 175 \quad 419$

Starspotted smoothhound $\quad 112 \quad 420$

Speckled smoothhound $\quad 130 \quad 420$

Venezuelan dwarf smoothhound $57 \quad 421$

Arabian smoothhound $\quad 150 \quad 421$

Smoothhound $\quad 164 \quad 422$

Narrowfin smoothhound $\quad 98 \quad 422$

Whitespot smoothhound $\quad 113 \quad 423$

Blackspot smoothhound $\quad 95 \quad 423$

Australian grey smoothhound $\quad 101 \quad 424$

Narrownose smoothhound $\quad 109 \quad 424$

Gulf of Mexico smoothhound $\quad 140 \quad 425$

Whitespotted gummy shark $\quad 103 \quad 425$

Eastern spotted gummy shark $\quad 112 \quad 426$

Humpback smoothhound $\quad 87 \quad 426$

Whitefin smoothhound $\quad 110 \quad 427$

Flapnose houndshark $\quad 102 \quad 427$

Sharpfin houndshark $\quad 102 \quad 428$

Spotted houndshark $\quad 240 \quad 428$

Spotted gully shark $\quad 208 \quad 429$

Banded houndshark $\quad 150 \quad 429$

Leopard shark $\quad 210 \quad 430$ 
411 Chaenogaleus macrostoma

412 Hemigaleus australiensis

413 Hemigaleus microstoma

414 Hemipristis elongatus

415 Paragaleus leucolomatus

416 Paragaleus pectoralis

417 Paragaleus randalli

418 Paragaleus tengi

Carcharhinidae

419 Carcharhinus acronotus

420 Carcharhinus altimus

421 Carcharhinus albimarginatus

422 Carcharhinus amblyrhynchos

423 Carcharhinus amblyrhynchoides

424 Carcharhinus amboinensis

425 Carcharhinus borneensis

426 Carcharhinus cautus

427 Carcharhinus coatesi

428 Carcharhinus brachyurus

429 Carcharhinus brevipinna

430 Carcharhinus dussumieri

431 Carcharhinus fitzroyensis

432 Carcharhinus falciformis

433 Carcharhinus galapensis

434 Carcharhinus hemiodon

435 Carcharhinus isodon

436 Carcharhinus leiodon

437 Carcharhinus macloti

438 Carcharhinus leucas

439 Carcharhinus limbatus

440 Carcharhinus longimanus

441 Carcharhinus melanopterus

442 Carcharhinus porosus

443 Carcharhinus obscurus

444 Carcharhinus plumbeus

445 Carcharhinus perezi

446 Carcharhinus sealei

447 Carcharhinus signatus

448 Carcharhinus sorrah

449 Carcharhinus tilsoni

450 Carcharhinus tjutjot

451 Galeocerdo cuvier

452 Glyphis fowlerae

453 Glyphis gangeticus

454 Glyphis garricki

455 Glyphis glyphis
Hooktooth shark $\quad 100$

Australian weasel shark $\quad 110$

431

Sicklefin weasel shark $\quad 94$

Snaggletooth shark 240

Whitetip weasel shark

Atlantic weasel shark

Slender weasel shark

96

$138 \quad 436$

$81 \quad 436$

Straighttooth weasel shark

88

437

Blacknose shark

137

300

300

Silvertip shark

255

178

280

70

150

88

294

278

100

135

330

370

102

200

142

110

340

255

395

200

150

400

300

295

95

280

160

200

94

740

200

204

300

300

456

456

457

458

459

459

460

460

461

461

462

463

463

464

465

466

466

467

467

468

469

470

471

471

472

473

474

474

475

475

476

476

477

478

479

479

Speartooth shark

482 
456 Glyphis siamensis

457 Isogomphodon oxyrhynchus

458 Lamiopsis temmincki

459 Lamiospsis tephrodes

460 Loxodon macroorhinus

461 Nasolamia velox

462 Negaprion acutidens

463 Negaprion brevirostris

464 Prionace glauca

465 Rhizoprionodon acutus

466 Rhizoprionodon lalandei

467 Rhizoprionodon longurio

468 Rhizoprionodon oligolinx

469 Rhizoprionodon porosus

470 Rhizoprionodon taylori

471 Rhizoprionodon terraenovae

472 Scoliodon laticaudus

473 Scoliodon macrorhynchos

474 Trianodon obesus

Sphyrnidae

475 Eusphyra blochii

476 Sphyrna corona

477 Sphyrna media

478 Sphyrna lewini

479 Sphyrna mokarran

480 Sphyrna tiburo

481 Sphyrna tudes

482 Sphyrna zygaena
Irrawaddy river shark

300

Daggernose shark 244

Broadfin shark 168

Borneo broadfin shark

145

99

150

310

340

380

178

77

154

70

110

67

110

74

71

213

186

92

150

420

610

150

150

400

482

483

483

492

492

493

493

494

495

496

496

497

497

498

498

499

499

500

500

Winghead shark

501

Scoophead shark

506

Scalloped hammerhead

Great hammerhead

506

Bonnethead shark

507

Smalleye hammerhead

508

Smooth hammerhead 
Appendix 2. List of museum specimens by family used for pilot study (see Materials and Methods) along with the representative species examined (see Appendix 1 for species code) as well as its total length (TL; in $\mathrm{cm}$ ), sex, and locality data.

\begin{tabular}{|c|c|c|c|c|c|}
\hline Order and family & Code & Specimen & TL & Sex & Locality \\
\hline \multicolumn{6}{|l|}{ HEXANCHIFORMES } \\
\hline Chlamydoselachidae & 1 & SAM 31028 & 117 & $\mathrm{~F}$ & Namibia \\
\hline Hexanchidae & 3 & FMNH 76185 & 45 & $\mathrm{~F}$ & Japan \\
\hline \multicolumn{6}{|l|}{ ECHINORHINIFORMES } \\
\hline Echinorhinidae & 8 & LACM 33827.031 & 66 & $?$ & North Pacific Ocean \\
\hline \multicolumn{6}{|l|}{ SQUALIFORMES } \\
\hline Squalidae & 12 & FMNH 31201 & 65 & M & Battle Harbor \\
\hline Centrophoridae & 47 & FMNH 74190 & 40 & M & Japan \\
\hline Etompteridae & 76 & FMNH 65547 & 20 & M & Caribbean Sea \\
\hline Somniosidae & 111 & MCZ 39609 & 127 & M & North Atlantic \\
\hline Oxynotidae & 118 & UF 41669 & 25 & $\mathrm{~F}$ & Namibia \\
\hline Dalatiidae & 121 & MCZ S-1116 & 115 & M & Japan \\
\hline \multicolumn{6}{|l|}{ PRISTIOPHORIFORMES } \\
\hline Pristiophoridae & 134 & FMNH 76686 & 67 & $\mathrm{~F}$ & Japan \\
\hline \multicolumn{6}{|l|}{ SQUATINIFORMES } \\
\hline Squatinidae & 139 & UMMZ 179075 & 39 & $\mathrm{~F}$ & Japan \\
\hline \multicolumn{6}{|l|}{ HETERODONTIFORMES } \\
\hline Heterodontidae & 142 & UMMZ 179075 & 39 & $\mathrm{~F}$ & Japan \\
\hline \multicolumn{6}{|l|}{ LAMNIFORMES } \\
\hline Mitsukurinidae & 149 & SIO 07-46 & 115 & M & Japan \\
\hline Odontaspididae & 151 & ВРВM 9334 & 190 & $\mathrm{~F}$ & Hawaii, USA \\
\hline Pseudocarchariidae & 153 & FMNH 117474 & 101 & M & Hawaii, USA \\
\hline Megachasmidae & 154 & SIO 07-53 & 215 & $\mathrm{~F}$ & Mexico \\
\hline Cetorhinidae & 155 & MCZ 54413 & 385 & $\mathrm{~F}$ & Massachusetts, USA \\
\hline Alopiidae & 158 & UF 160188 & 187 & M & Florida, USA \\
\hline Lamnidae & 162 & USNM 201731 & 79 & $\mathrm{~F}$ & "Pacific" \\
\hline \multicolumn{6}{|l|}{ ORECTOLOBIFORMES } \\
\hline Parascylliidae & 171 & SAMA F3563 & 46 & $?$ & South Australia \\
\hline Brachaeularidae & 173 & USNM 197619 & $?$ & $?$ & Pacific \\
\hline Orectolobidae & 178 & UMMZ 179035 & 86 & $\mathrm{~F}$ & Japan \\
\hline Hemiscylliidae & 193 & FMNH 21875 & 39 & M & Indo-Pacific \\
\hline Stegostomatidae & 201 & UMMZ 218253 & 115 & $\mathrm{~F}$ & Thailand \\
\hline Ginglymostomatidae & 203 & FMNH 8180 & 38 & $\mathrm{~F}$ & Falkland Islands \\
\hline Rhincodontidae & 205 & OS 18090 & $?$ & $?$ & $?$ \\
\hline \multicolumn{6}{|l|}{ CARCHARHINIFORMES } \\
\hline Scyliorhinidae & 280 & FMNH 74116 & 29 & M & Japan \\
\hline Proscylliidae & 356 & CAS 28577 & 60 & $\mathrm{~F}$ & Taiwan \\
\hline Pseudotriakidae & 358 & NMNZ P.001509 & 93 & $?$ & New Zealand \\
\hline Leptochariidae & 363 & FMNH 118126 & 25 & M & South Atlantic \\
\hline
\end{tabular}


Triakidae

Hemigaleidae

Carcharhinidae

Sphyrnidae
382 UMMZ 86204

414 LACM 37712.001

439 FMNH 121470

480 FMNH 62438
$70 \quad \mathrm{~F}$

$76 \quad \mathrm{~F}$

$102 \mathrm{~F}$

$49 \quad \mathrm{M}$
Long Island, USA

Indian Ocean

Alabama, USA

Panama Bay 
Appendix 3. Geometric morphometric plots (small dots) of full body analysis with species codes (see Appendix 1; cf. Fig. 4B). Overlapping numbers are appreciably difficult or impossible to read, but this illustration is intended to at least show codes of species present at extremities or representing outliers.

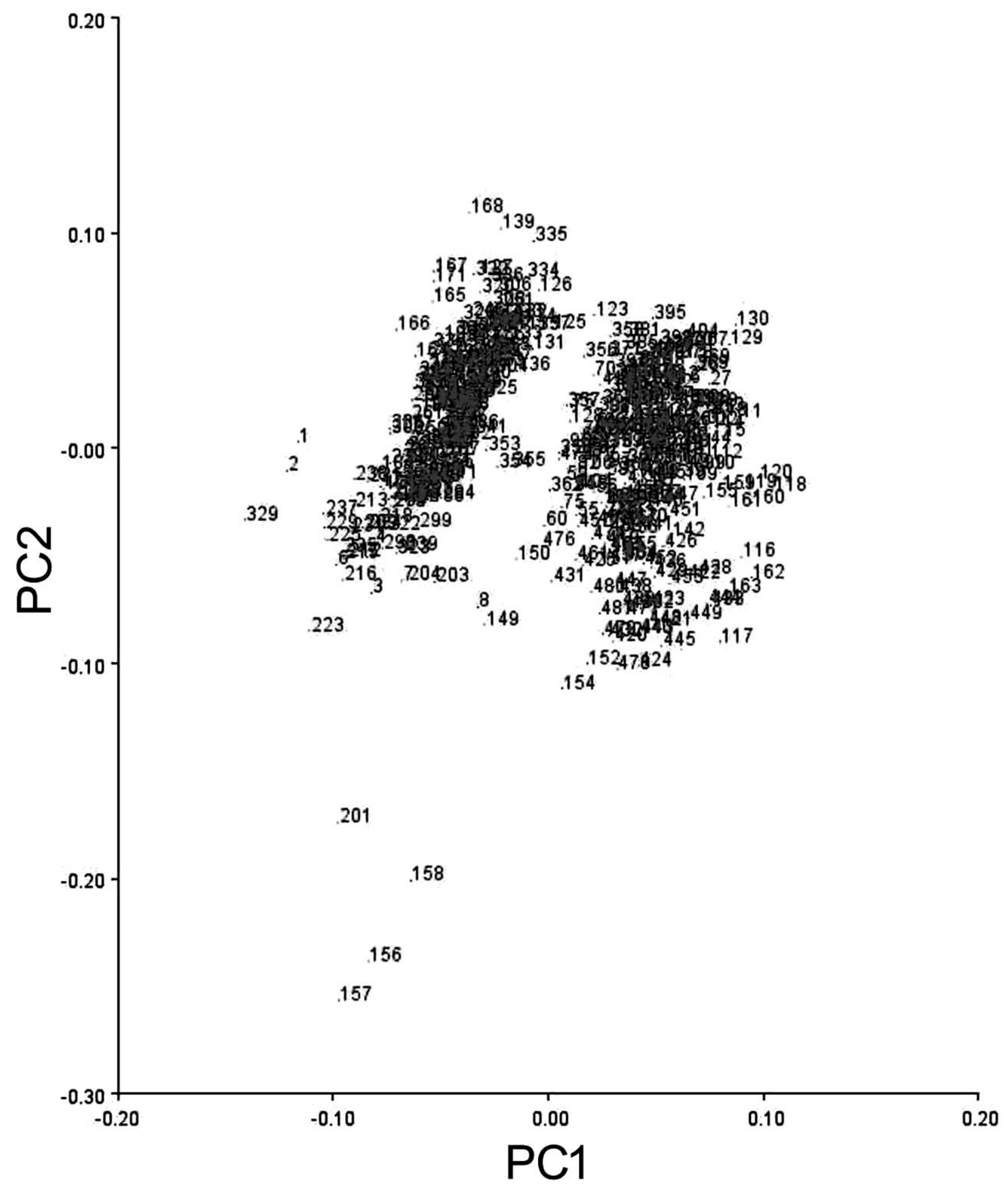


Appendix 4. Geometric morphometric plots of full body analysis with principle components 1 and 3. Percentage in parentheses in each axis denotes percent variation explained by that principle component.

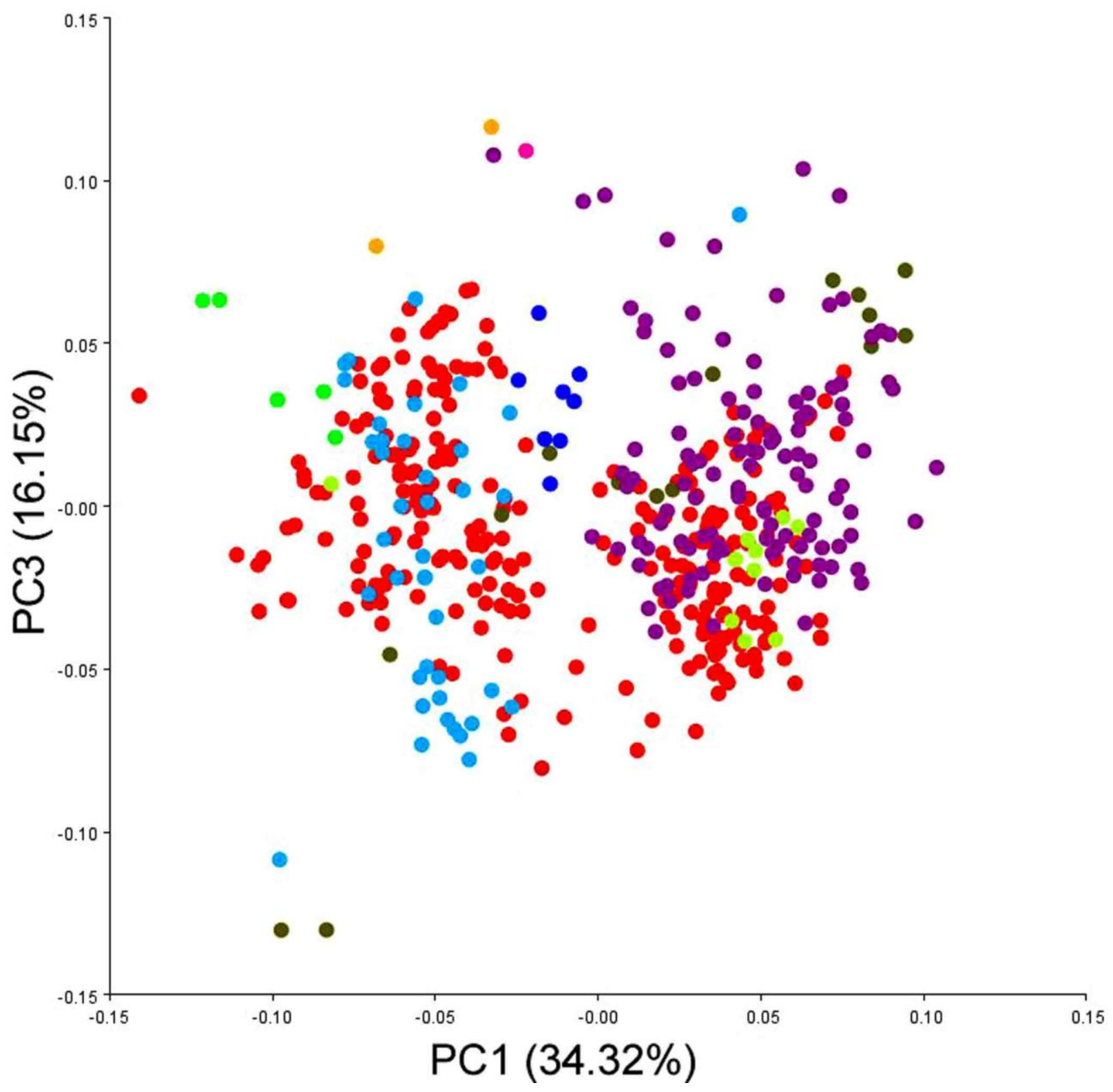


Appendix 5. Geometric morphometric plots of full body analysis with principle components 1 and 4. Percentage in parentheses in each axis denotes percent variation explained by that principle component.

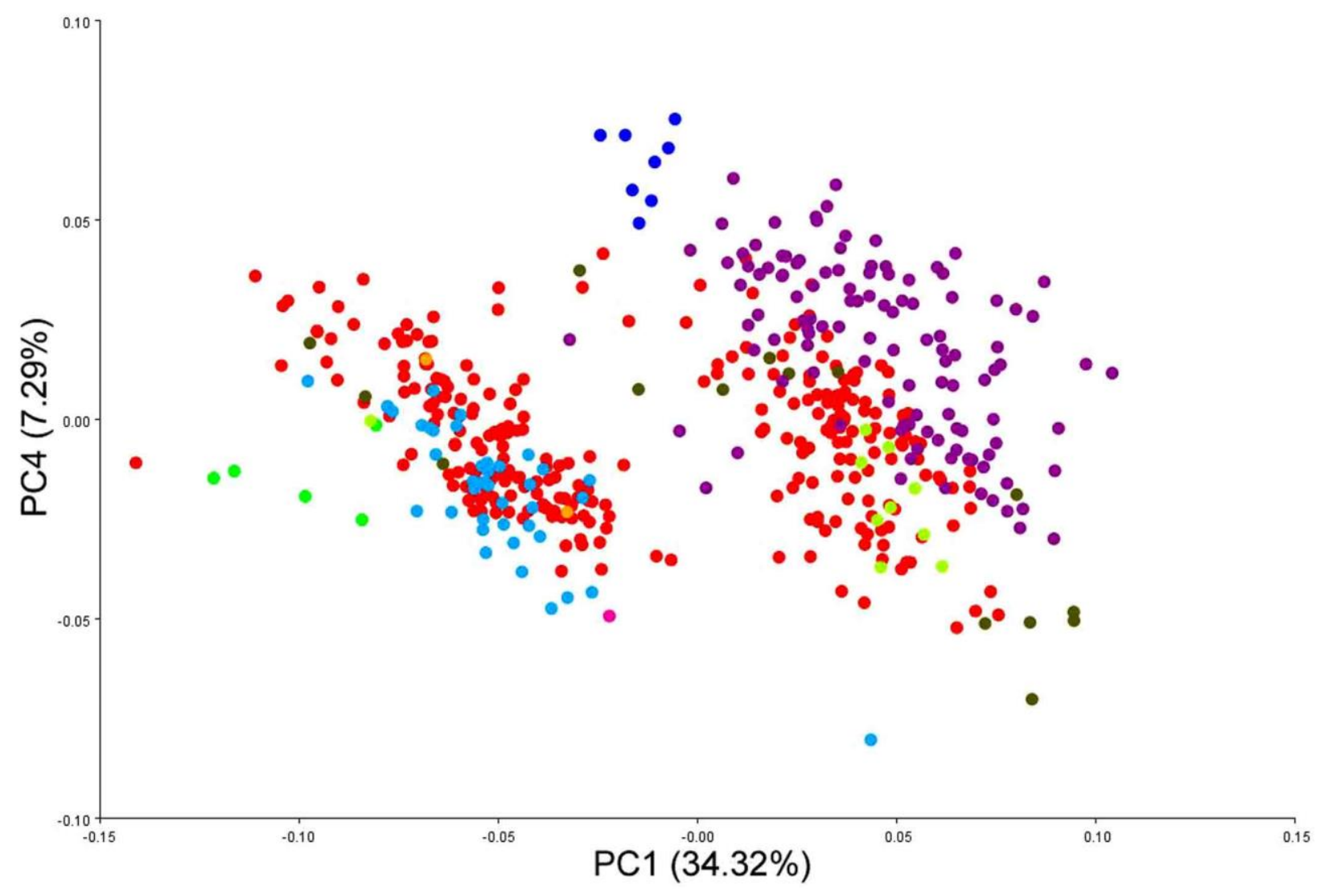


Appendix 6. Geometric morphometric plots of full body analysis with principle components 1 and 5. Percentage in parentheses in each axis denotes percent variation explained by that principle component.

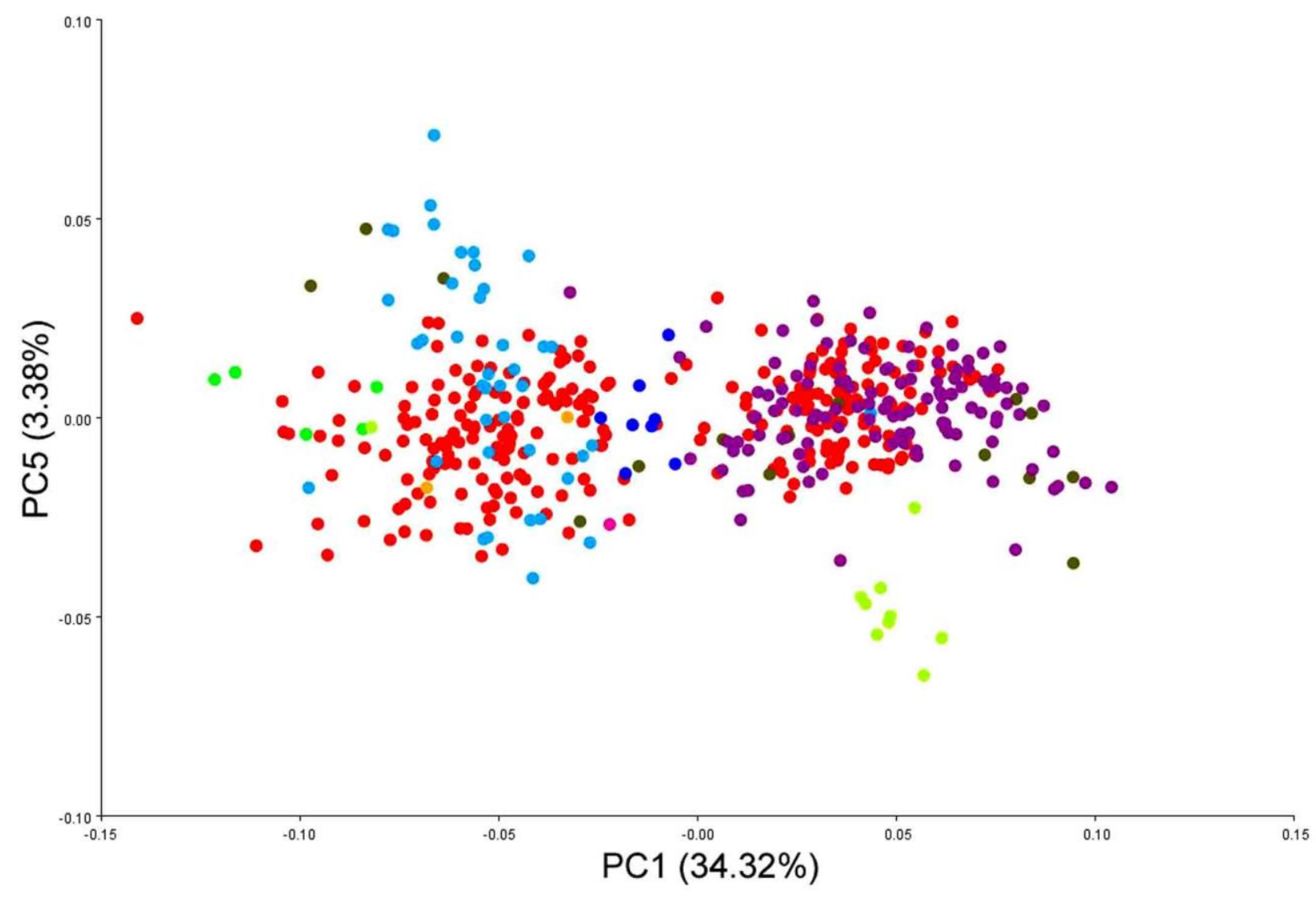


Appendix 7. Geometric morphometric plots (small dots) of precaudal body analysis with species codes (see Appendix 1; cf. Fig. 4C). Overlapping numbers are appreciably difficult or impossible to read, but this illustration is intended to at least show codes of species present at extremities or representing outliers.

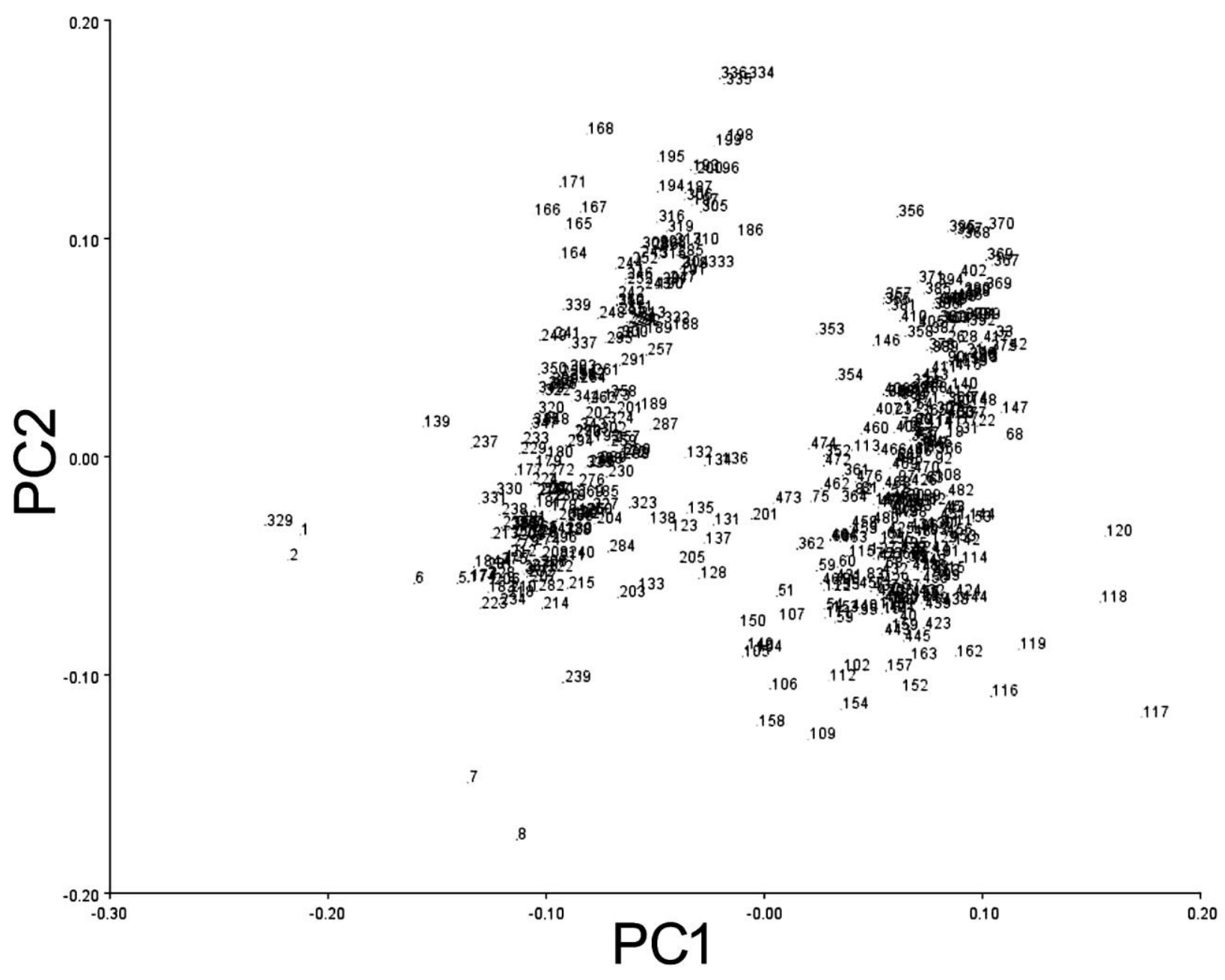


Appendix 8. Geometric morphometric plots (small dots) of caudal fin analysis with species codes (see Appendix 1; cf. Fig. 4D). Overlapping numbers are appreciably difficult or impossible to read, but this illustration is intended to at least show codes of species present at extremities or representing outliers.

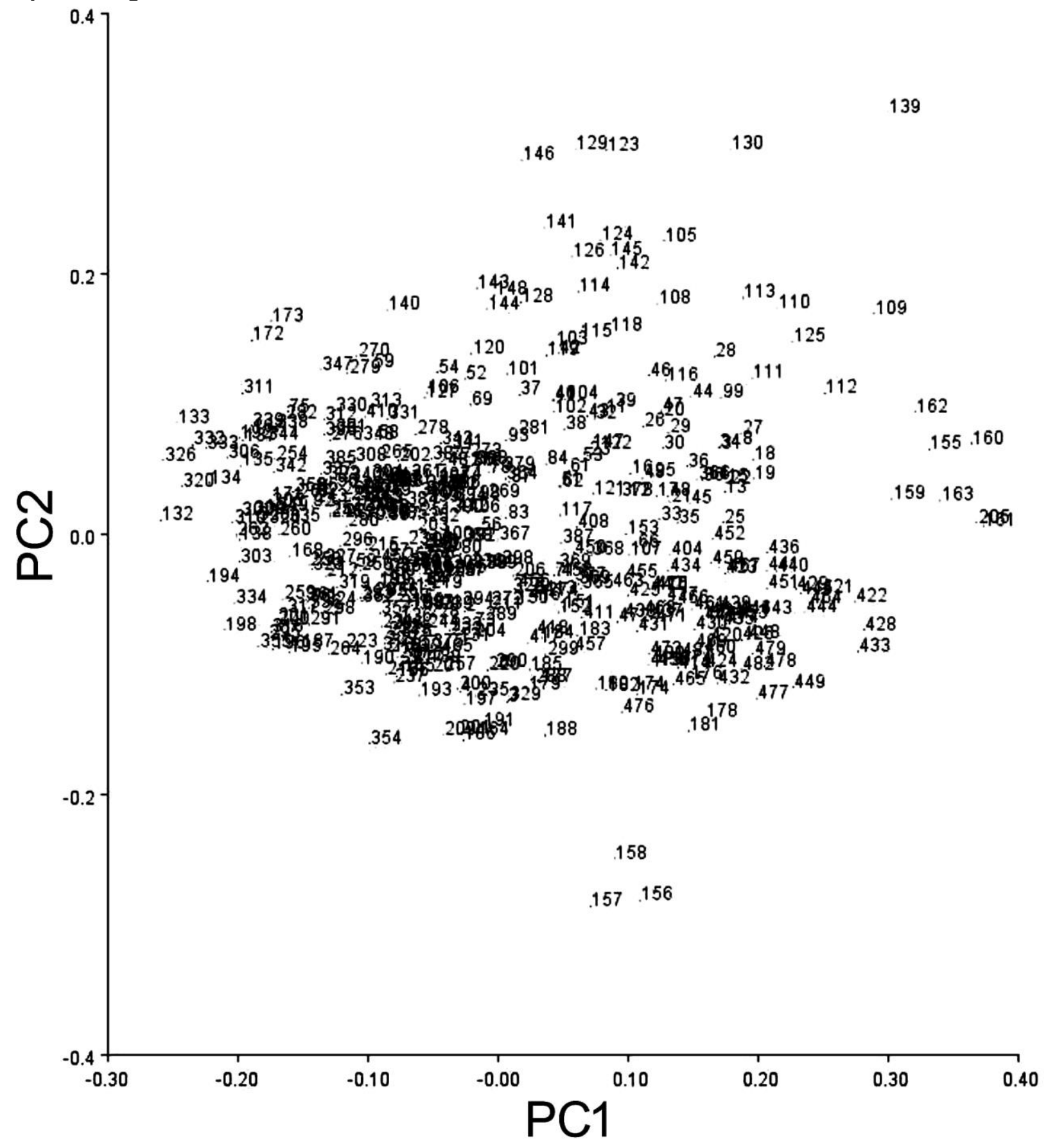

